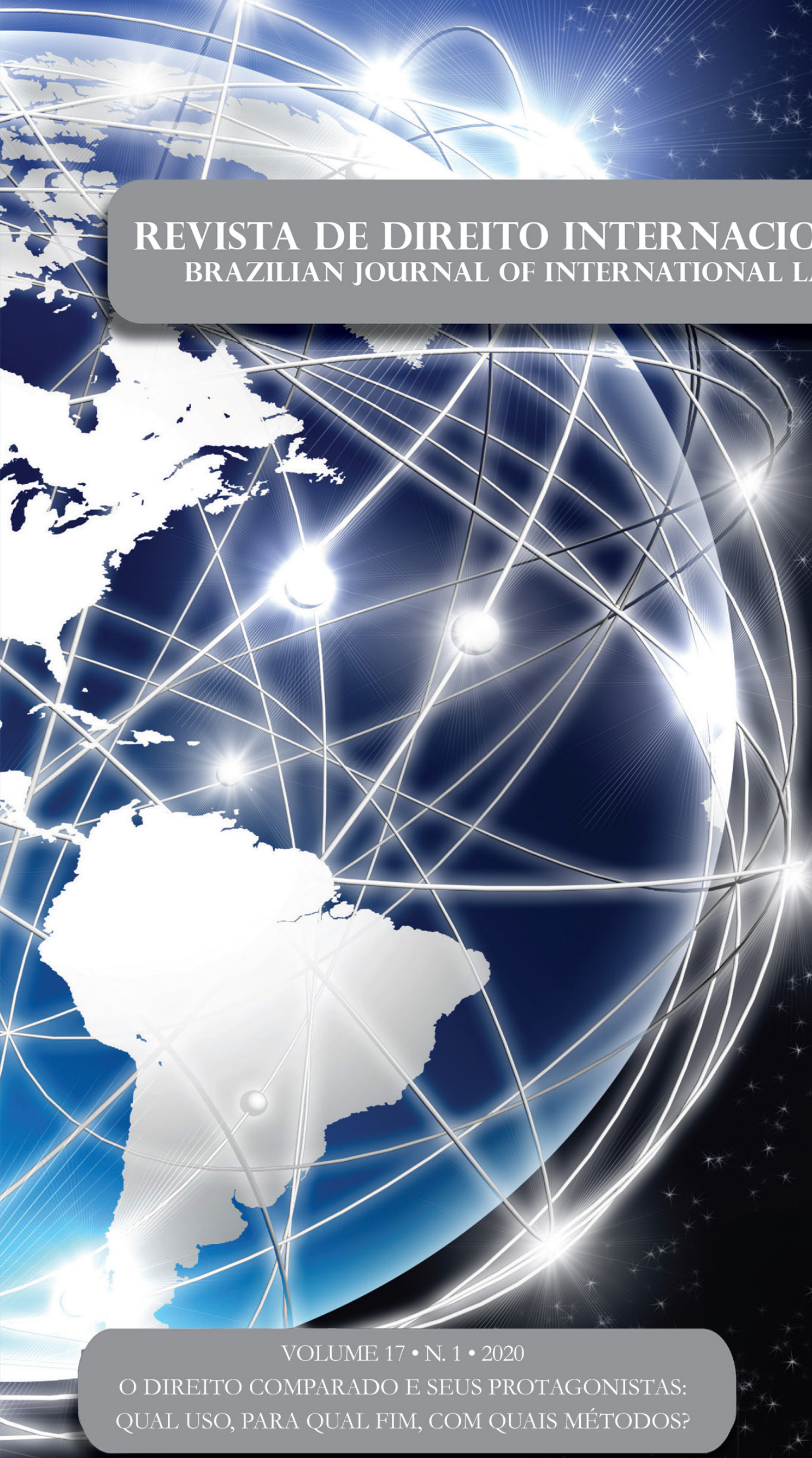

La otra cara de la moneda: protección constitucional de la empresa, el emprendimiento y la libre competencia en Chile y Colombia

The other side of the coin: constitutional protection of the company, entrepreneurship and free competition in Chile and Colombia

Juan Pablo Díaz Fuenzalida Juan Sebastián Villamil Rodríguez 
Parte I - O Direito comparado e seus Protagonistas: QuAL uso, PARA QUAL FIM, COM QUAIS MÉTODOS? .....................................................................1

EDITORIAL ............................................................................................................... 3

"Tudo o que precisamos fazer é ter certeza de que continuaremos conversando".............................. 3

Gustavo Cerqueira e Patrícia Perrone Campos Mello

Direito comparado E METOdologia $\quad$................................................... 6

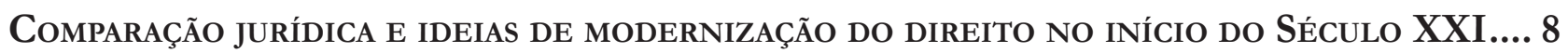
Gustavo Cerqueira

O DIREITO COMPARADO: ESFORÇO DE RESGATE HISTORIOGRÁFICO E DE PROBLEMAS METODOLÓGI$\cos$

Arnaldo Sampaio de Moraes Godoy e Gustavo Fereira Ribeiro

Direito Comparado e Política: Reflexões Necessárias .42

Raphael Carvalho de Vasconcelos e Deo Campos Dutra

Direito comparado no Brasil

L'originalité du Droit Brésilien et le Droit Comparé .57

Arnoldo Wald

LEI DA BOA RAZÃo E COMPARATISMO JURÍDICO NA DOUTRINA CIVILISTA BRASILEIRA DE 1850 A 1880

Alan Wruck Garcia Rangel

O STF EM REDE? QUANTO, COMO, COM QUE ENGAJAMENTO ARGUMENTATIVO O STF USA PRECEDENTES ESTRANGEIROS EM SUAS DECISÕES?

Patrícia Perrone Campos Mello e Felipe Meneses Graça 
Suprema Imprecisão: a metodologia em Direito Constitucional Comparado E as deficiênCias Em Seu uso pelo Supremo Tribunal Federal

Alonso Freire e Hugo Sauaia

Direitos comparados

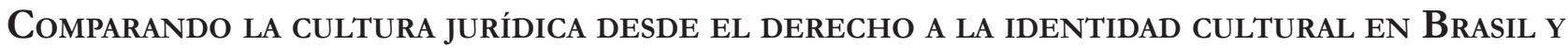

CHILE 145 Juan Jorge Faundes e Fabian Le Bonniec

O Divino e o Racional no Direito: notas para um diálogo entre sistemas jurídicos 181 Salem Hikmat Nasser e José Garcez Ghirardi

Regulação do discurso de Ódio: análise comparada em países do Sul Global 196 Jane Reis Gonçalves Pereira, Renan Medeiros de Oliveira e Carolina Saud Coutinho

Parte II - Outros temas

LA OTRA CARA DE LA MONEDA: PROTECCIÓN CONSTITUCIONAL DE LA EMPRESA, EL EMPRENDIMIENTO Y LA LIBRE COMPETENCIA EN CHILE y COLOMBiA

Juan Pablo Díaz Fuenzalida e Juan Sebastián Villamil Rodríguez

The European Court of Human Rights Decision on there 'Burqa Ban'and the CritiCal analysis of the Pragmatic experimental logic 258 Flavianne Fernanda Bitencourt Nóbrega e George Browne Rego

Direitos humanos das deslocadas ambientais e os impactos da Usina de Belo Monte: da EXPLORAÇÃO AMAZÔNICA À SUBJUGAÇÃO FEMININA

Thais Silveira Pertille e Letícia Albuquerque

Solução de Controvérsias em Acordos de Investimento: as experiênCias do CPTPP, CETA E DOS ACFIs

Fábio Morosini, Vivian Daniele Rocha Gabriel e Anastacia Costa

50 anos dos “direitos da Criança” na Convenção Americana de Direitos Humanos: a HISTÓRIA DO ARTIGO 19 311

Sven Peterke e Paloma Leite Diniz Farias 
EMPRESAS E DIREITOS HUMANOS: COMPARTILHANDO VALOR E RESPONSABILIDADES .325 Melina Girardi Fachin

CONTEMPORARY RESPONSES TO BUSINESSES' NEGATIVE HUMAN RIGHTS IMPACT 341 Andres Felipe Lopez

Human Right to LABOR PROTECTION IN UKRAINE: CURRENT SITUATION AND THE PROSPECTS OF IMPLEMENTATION OF INTERNATIONAL RULES 363 Nina Daraganova

International Regulation and Global Governance: The EU influential Method IN TIMES OF NORMATIVITY CHANGE 373 Gabriela Hühne Porto, Paula Wojcikiewicz Almeida e Juliana Maia F. A. Netto

Tecnologias digitais e o comércio de bens E SERviços na OMC/Digital. 391 Umberto Celli Junior

Los fuertes hacen lo QUe PUeden: exponiendo los límites de la Corte Penal InternaCIONAL .406

Cristián D. González-Ruiz e Víctor M. Mijares

Human Rights, Humanitarian Law and State Power 418 Renata Nagamine e João Roriz

Regional integration in the South Pacific: Challenges for Public governance .433 Joanna Siekiera

Parte III - Resenhas 443

RESENHA DA OBRA

“Democracia e policentrismo do poder", de Murilo Gaspardo 445 Angela Limongi Alvarenga Alves 


\section{La otra cara de la moneda: protección constitucional de la empresa, el emprendimiento y la libre competencia en Chile y Colombia*}

\author{
The other side of the coin: constitutional \\ protection of the company, entrepreneurship \\ and free competition in Chile and Colombia
}

* Recebido em 12/12/2019

Aprovado em 19/04/2020

** Doctor en Derecho, Máster en Gobernanza y Derechos Humanos, ambos por la Universidad Autónoma de Madrid; Licenciado en Ciencias Jurídicas y Sociales, Magister en Docencia Universitaria, ambos por la Universidad Autónoma de Chile; abogado, título otorgado por la Excelentísima Corte Suprema de Chile; Profesor Investigador en estancia post-doctoral en la Universidad Pablo de Olavide, Sevilla, gracias a una beca de la Asociación Universitaria Iberoamericana de Postgrado (AUIP); becario para cursar programa para Jóvenes Líderes Iberoamericanos por la Fundación Carolina de España. Es Investigador responsable del proyecto Fondecyt de Postdoctorado 2020 ( $N^{\circ}$ 3200477) titulado: "Instituto Nacional de Derechos Humanos (INDH): Evaluación de sus 10 años de protección y promoción de los derechos humanos en los tribunales de justicia en Chile"; Profesor de Derecho Constitucional adscrito al Instituto de Investigación en Derecho de la Universidad Autónoma de Chile y profesor del programa Teaching in Chile de la misma casa de estudios; Editor alterno de la Revista Justicia y Derecho de la Universidad Autónoma de Chile. Filiación institucional Universidad Autónoma de Chile.

Correo electrónico: juanpablo.diaz@uautonoma.cl / jpdiazfuenzalida@gmail.com

*** Abogado, Universidad del Rosario, Bogotá, Colombia; Máster en Derechos Fundamentales y Libertades Públicas, Universidad de Castilla la Mancha, España; Especialista en Derecho Sustantivo y Contencioso Constitucional de la Pontificia Universidad Javeriana Universidad Javeriana, Colombia, y, Doctorando en Derecho de la Universidad Autónoma de Madrid, España. Profesor de Derecho Constitucional, filiación institucional, Universidad Colegio Mayor de Nuestra Señora del Rosario, Colombia.

Correo de contacto: juan.villamil@predoc.uam.es
Juan Pablo Díaz Fuenzalida**

Juan Sebastián Villamil Rodríguez***

\section{Resumen}

El presente trabajo estudia la protección constitucional de la empresa, el emprendimiento y la libre competencia en Chile y Colombia. Para lograr aquello, se realiza un estudio en derecho comparando ambos países, en que se analizan las acciones o recursos constitucionales de los que pueden ser sujetos activos legitimados los emprendedores y cómo se relaciona con la libre competencia. Considera en su desarrollo doctrina jurídica, análisis de normativa y de jurisprudencia relevante. Destaca entre las conclusiones que en ambos sistemas estudiados al emprendimiento o, inclusive, a las empresas, se les reconozca una serie de derechos y libertades fundamentales, y, además, ser sujetos activos legitimados de una serie de acciones y recursos constitucionales. No obstante, y, al mismo tiempo, la actividad económica debe estar en armonía con los derechos humanos de los demás en una faceta que reconoce no solo los derechos sino las obligaciones de la empresa en el marco del Estado constitucional. De ahí lo de las dos caras de la moneda, derecho fundamental de emprender, pero respetando los derechos fundamentales de los demás. Y, como perspectivas de futuro, elevar el emprendimiento, de libertad a un derecho justiciable, especialmente cuando este sea una actividad de subsistencia, en el que la libre competencia también tiene un rol de garantía para la función de la propiedad.

Palabras clave: Emprendimiento. Empresa. Libre competência. Recurso de protección. Acción de tutela. Recurso de amparo.

\section{Resumo}

Este trabalho estuda a proteção constitucional da empresa, o empreendedorismo e a livre concorrência no Chile e na Colômbia. Para tanto, foi realizado um estudo jurídico que compara os dois países, nos quais são analisadas as ações ou recursos constitucionais dos quais os empresários podem ser legitimados como sujeitos ativos, esta parte sendo relacionada à livre concorrência no estudo. Em seu desenvolvimento, considera-se a doutrina jurídica, a 
análise de regulamentos e jurisprudência relevante. Destaca-se entre as conclusões que em ambos os sistemas estudados empreendedorismo ou mesmo empresas, são reconhecidos uma série de direitos e liberdades fundamentais, além de serem sujeitos ativos legitimados de uma série de ações e recursos constitucionais. No entanto, e ao mesmo tempo, a atividade econômica deve estar em harmonia com os direitos humanos de terceiros, em uma faceta que reconheça não apenas os direitos, mas também as obrigações da empresa no âmbito do Estado constitucional. Daí os dois lados da moeda, um direito fundamental de empreender, mas respeitando os direitos fundamentais dos outros. E, como perspectivas para o futuro, elevar o empreendedorismo, da liberdade a um direito justificável, especialmente quando se trata de uma atividade de subsistência, na qual a livre concorrência também tem um papel de garantia para a função da propriedade.

Palavras-chave: Empreendedorismo; empresa; livre concorrência; recurso de proteção; ação de tutela; recurso de amparo

\section{Abstract}

This paper studies the constitutional protection of business, entrepreneurship, and free competition in Chile and Colombia. The research provides with a review of law of both countries, analyzing the actions and constitutional resources in which entrepreneurs can be legitimate active subjects, as well as the constitutional approach to free competition. Consider its development in the legal doctrine, research of regulations, and relevant jurisprudence. Among the conclusions, it stands out that in both States entrepreneurship or even companies possess a series of fundamental rights and freedoms that legitimize their relation to the state and other subjects of the law. Due to this, companies are not only strictly accountable in terms of their human rights obligations but hold certain prerogatives that concede them a protection in a market where they co-exist with the State and larger corporations. Hence, both sides of this matter include, on the one hand, the obligations that corporations have regarding human rights and, on the other hand, a series of constitutional actions and remedies that elevate entrepreneurship to a justiciable right that protects small-scale entrepreneurship, due to the high social importance of small scale business for the materialization of the social functions of property.

Keywords: Entrepreneurship. Company. Free competition. Protection remedy. Guardianship action. Amparo appeal.

\section{Introducción: derecho constitucional de la empresa, del emprendimiento y a libre competencia ¿Será justiciable?}

El lenguaje de derecho constitucional y empresa habitualmente refiere al potencial lesivo que tienen las corporaciones sobre los derechos fundamentales de las personas naturales ${ }^{1}$. Dentro de este género, se han enunciado por ejemplo: la conducta empresarial y su responsabilidad ${ }^{2}$; las violaciones que pueden sufrir los trabajadores de las empresas ${ }^{3}$, enfocándose inclusive en casos relevantes de grandes industrias de confección de ropa ${ }^{4}$ o de problemas en las cadenas de producción trasnacional contrarias a los derechos humanos ${ }^{5}$; o, en relación con el medio ambiente ${ }^{6}$, por ejemplo, con las

1 Véase sobre los principios guía sobre empresa y derechos humanos: VILMONDES TURKE, Mariana Aparecida. Business and human rights in Brazil: exploring human rights due diligence and operational-level grievance mechanisms in the case of Kinross Paracatu gold mine. Brazilian Journal of International Law, Brasilia, v. 15, n. 2, p. 223-241, 2019.

2 JOS, Justin. Access to remedies and the emerging ethical dilemmas: changing contours within the business-human rights debate. Brazilian Journal of International Law, Brasilia, v. 15, n. 2, p. 117-128, 2018.

3 MATOS, Laura Germano; MATIAS, João Luis Nogueira. Multinacionais fast fashion e direitos humanos: em busca de novos padrões de responsabilização. Brazilian Journal of International Law, Brasilia, v. 15 , n. 2, p. 254-268, 2018; sobre el potencial que tiene leyes de mercado justo que vinculan a las compañias a practicas empresariales responsales vease: MENDES Danielle, THAME Denn. Brazilian Journal of International Law, Brasilia, v. 15, n. 2, p. 203-220, 2018.

4 MATOS, Laura Germano; MATIAS, João Luis Nogueira. Zara, M. Officer, Pernambucanas e Serafina/Collins: o padrão condenatório por condições degradantes da mão de obra em redes contratuais do setor de vestuário. Brazilian Journal of International Law, Brasilia, v. 16, n. 3, p. 111-131, 2019.

5 Sobre la eventual compatibilidad de ciertas operaciones extractivas de recursos naturales y el sistema inter-Americano véase: DO AMARAL, Junior, PALACIO REVELLO, Viviana. Human rights and extractive industries in Latin America: what responsibility of corporations and their States of origin for human rights violations in the Inter-American Rights System? Brazilian Journal of International Law, Brasilia, v. 15, n. 2, pp. 244-252, 2018.

6 Sobre la relación entre el concepto de empresa, derechos humanos, y medio ambiente véase: AUZ VACA, Juan Gabriel. The environmental law dimensions of an international binding treaty on business and human rights. Brazilian Journal of International Law, 
problemáticas de responsabilidad respecto de aumento de riesgo en exploración de petróleo en aguas profundas, concretamente complejidades jurisdicción ${ }^{7}$; o, de aquellas buenas prácticas que podrán volverse obligatorias, como los códigos y declaraciones empresariales que tratan sobre derechos humanos ${ }^{8}$ y el dialogo entre fuentes nacionales con el llamado control de convencionalidad, para que la actividad económica y empresarial sea sustentable?

Renglón seguido, al escuchar derecho y empresa, se hace un enfoque en las corporaciones en el contexto del derecho comercial, en muchas ocasiones, desde un punto de vista "corporativo", podríamos llamar, siendo de los últimos: la relevancia de los grupos de empresas en el mercado transnacional ${ }^{10}$; o bien, cómo en el mundo globalizado pueden actuar, a través de lo que se ha llamado meta-derecho que traspasa fronteras ${ }^{11}$; o bien, su regulación a nivel nacional, pero de rango legal, como en casos de eventuales trabas comerciales o protección de la salud ante los nuevos rotules que deben tener algunos alimentos ${ }^{12}$; o, la defensa comercial internacional relacionada con tributos y aranceles en importaciones ${ }^{13}$.

Brasilia, v. 15, n. 2, pp. 152-187, 2018.

VARELA, Marcelo D. A necessidade de repensar os mecanismos de responsabilidade ambiental em caso de riscos de vazamento de petróleo na Zona Econômica Exclusiva do Brasil. Brazilian Journal of International Law, Brasilia, v. 12, n. 1, p. 240-249, 2015; sobre la relación del sector extractivo y las convenciones regionales de derechos humanos véase: WOODS, Cindy S. Engaging the U.N. Guiding Principles on Business and Human Rights: the Inter-American commission on human rights \& extractive sector. Brazilian Journal of International Law, Brasilia, v. 12, n. 2, pp. 572-588, 2015.

8 SANTARELLI, Nicolás Carrillo. Declaraciones empresariales "voluntarias" sobre derechos humanos, y la necesidad de una regulación institucional (internacional e interna) externa. Brazilian Journal of International Law, Brasilia, v. 16, n. 3, p. 21-49, 2019.

9 GOMEZ, Eduardo Biacchi; MARINOZZI, Julia Colle. O diálogo entre fontes normativas e o controle de convencionalidade: entre o livre comércio e o desenvolvimento econômico e sustentável. Brazilian Journal of International Law, Brasilia, v. 16, n. 1, p. 186-199, 2019; RUY CARDIA, Ana Claúdia. Reparation of victims in light of a treaty on business and human rights. Brazilian Journal of International Law, Brasilia, v. 15, n. 2, p. 3-11, 2018.

10 FERRAZ, Daniel Amin. Grupo de sociedades: instrumento jurídico de organização da empresa plurissocietária. Brazilian Journal of International Law, Brasilia, v. 12, n. 2, pp. 494-510, 2014.

11 FERRAZ, Daniel Amin. Grupo de sociedades: instrumento jurídico de organização da empresa plurissocietária. Brazilian Journal of International Law, Brasilia, v. 12, n. 2, p. 494-510, 2014.

12 COBO, Nicolás. Ley de rotulación de alimentos de Chile: ¿Traba comercial o protección de la salud?. Brazilian Journal of International Law, Brasilia, v. 14, n. 3, p. 260-275, 2017.

13 OSORIO, Ricardo Serrano; COUTO, Clayton. A defesa comercial e a restrição da liberalização e da integração comercial pelo aumento da alíquota de IPI de veículos importados no Brasil. Brazilian
Sin embargo, el presente artículo lo que trata es la otra cara de la moneda del derecho constitucional en esta área, es decir, sobre la presencia constitucional de la empresa, la protección del emprendimiento y la libre competencia, como un ideal de resguardo. No obstante, en este hipotesis preliminar ya se anuncia que es justamente una moneda con dos caras, es decir, afirmamos el derecho de emprender es fundamental, pero a su turno, este tiene limitaciones, que están especialmente relacionadas con su función social ${ }^{14}$, lo que debe conllevar a un mejor disfrute de los derechos humanos.

En tal sentido, el eje central del presente trabajo el "emprendimiento". Como nos recuerda Rodríguez Ramírez, es un término que deriva del concepto francés de entrepreneur, que significa estar listo para tomar decisiones o iniciar algo ${ }^{15}$. En la misma línea está descrita en la Real Academia Española, como aquella acción y efecto de emprender ${ }^{16}$, y, ésta última relativa al acometer y comenzar una obra, un negocio, un empeño, especialmente si encierran dificultad o peligro ${ }^{17}$. Hoy los emprendedores son o deben ser más que agentes de compras de medios de producción. En efecto, Duarte y Ruiz refieren a la concepción de Joseph Shumpeter, profesor de la Universidad de Harvard, hace énfasis a que la función de los emprendedores es reformar el patrón de producción al explotar una invención o de proveer una nueva fuente de insumos, o de reorganizar la industria. Así, se podrá revolucionar el organismo económico y generar prosperidad $^{18}$.

El emprendimiento en América Latina también es relevante para el crecimiento y desarrollo, teniendo características propias que hacen necesarios saberes al respecto. En nuestra región, en un estudio de Sparano

Journal of International Law, Brasilia, v. 10, n. 1, p. 86-95, 2013.

14 PEREZ ÁlVAREZ, María del Pilar. La Función Social de la Propiedad Privada. Su protección jurídica. Revista Jurídica de la Universidad Autónoma de Madrid, Madrid, v. 30, n 2., p. 17-47, 2014.

15 RODRÍGUEZ RAMÍREZ, Alfonso. Nuevas perspectivas para entender el emprendimiento empresarial. Pensam. gest., Colombia, n. 26, p. 94-119, 2009.

16 REAL ACADEMIA ESPAÑOLA. Diccionario de la lengua española. Edición del Tricentenario. Actualización 2018, "emprendimiento". Disponible en: https://dle.rae.es/?id=Esj9hsT Acceso en: 28 jul. 2019.

17 REAL ACADEMIA ESPAÑOLA. Diccionario de la lengua española. Edición del Tricentenario. Actualización 2018, "emprender". Disponible en: https://dle.rae.es/?id=Esip2Nv Acceso en: 28 jul. 2019.

18 DUARTE, Tito; RUIZ TIBANA, Myriam. Emprendimiento, una opción para el desarrollo. Scientia Et Technica, Colombia, v. 15, n. 43, p. 326-331, 2009. 
Rada basado en datos del Global Competitiveness Report, el emprendimiento se ha expresado en dos tendencias. En efecto, por un lado, se relaciona en la generación de negocios, pero también en estrecha cercanía en aquellas personas que no tienen otra opción, es decir, que lo utilizan para sobrevivir. Así, el 42\% de los emprendedores identifican oportunidades de negociones, mientras que el 28\% lo hacen por necesidad. Y en la misma lógica nos indica que mientras más bajo el producto interno bruto, mayor emprendimiento y viceversa ${ }^{19}$. Así ratifica también Atienza, Lufín y Romaní, en un artículo que sintetiza esta visión titulado "más no siempre es mejor", añadiendo la idea de "trabajadores por cuenta propia" de "empleadores" 20. Así, emprendimiento no es solo objeto de grandes industrias, también es un quehacer del ciudadano promedio.

Para el caso particular de Chile, los datos son más que significativos sobre el emprendimiento. En efecto, según el Ministerio de Economía, Fomento y Turismo ${ }^{21}$, prácticamente la mitad de las empresas se constituyen como personas naturales $(49,1 \%)$, y, siguiendo las sociedades de responsabilidad limitada $(33,4 \%)$, siendo las sociedades anónimas relevantes para grandes empresas. $\mathrm{Y}$, que $48,3 \%$ son empresas familiares. En tal sentido, las microempresas $(48,7 \%)$ y las pymes $(48,6 \%)$ funcionan bajo dicha premisa. Así, se evidencia que el emprendimiento, ya sea por oportunidad o por necesidad, no es una actividad excluyente sólo de los grandes capitales. En tal sentido, merece determinar cómo se comporta el Derecho respecto a estas realidades en Latinoamérica. En una situación similar se encuentra Colombia, por ejemplo, en 2019 se crearon 309.463 siendo las microempresas un $99,6 \%$ del total, el 0,37\% las pequeñas y solo el $0,03 \%$ correspondían a medianas y grandes empresas $^{22}$. En Colombia, el emprendimiento se regula por

19 SPARANO RADA, Humberto. Emprendimiento en América Latina y su impacto en la gestión de proyectos. Revista Dimensión Empresarial, Colombia, v. 12, n. 2, p. 95-106, 2014.

20 ATIENZA, Miguel; LUFÍN, Marcelo; ROMANÍ, Gianni. Un Análisis espacial del emprendimiento en Chile. Más no siempre es mejor. Eure, Chile, v. 42, n. 127, pp. 111-135, 2016.

21 CHILE. Ministerio de Economía, Fomento y Turismo. Informe de resultados: Empresas en Chile. Cuarta Encuesta Longitudinal de Empresas. Agosto 2017. Disponible en: https://www.economia. gob.cl/wp-content/uploads/2017/03/Bolet $\%$ C3\%ADn-empresasen-Chile-ELE4.pdf. Acceso en: 28 jul. 2019.

22 Según datos de la Confederación de Cámaras de Comercio, la mayor concentración de nuevas empresas de acuerdo con su tamaño se presenta en las microempresas $(99,6 \%)$, seguido por las pequeñas empresas $(0,3 \%)$. Véase en CONFECÁMARAS. Dinámica de creación de empresas en Colombia. Enero-diciembre de 2019. Disponi- la denominada Ley de economía naranja (L. 1834 ${ }^{23}$ ) y por la Ley para el Fomento de la Micro, Pequeña y Mediana Empresa, (L. 59024). Ello evidencia que el emprendimiento no es una actividad exclusiva solo de grandes empresas, sino que para estos dos Estados que se toma de ejemplo, es mayoritariamente de los más pequeños, $y$, por tanto, de los ciudadanos comunes y corrientes.

Así, siendo relevante para los ciudadanos, y, especialmente para aquellos que emprenden por necesidad de subsistencia es menester dar una especial protección a la actividad. En tal sentido, no es suficiente que existan sólo normas jurídicas, también debe haber acciones o recursos judiciales efectivos hacer practicables los derechos. Así se ha dicho tanto por el Tribunal Europeo de Derechos Humanos ${ }^{25}$ como por la Corte Interamericana de Derechos Humanos ${ }^{26}$. En esa línea, se pretende estudiar, además de la normativa constitucional pertinente, a las acciones o recursos de los que podrían ser sujeto activos legitimados quienes realicen actividades empresariales o emprendimiento. No obstante, es menester señalar que se delimita el objeto de estudio sólo a los medios procesales de índole constitucional, o que protejan derechos constitucionales relacionados con la empresa o con el emprendimiento.

Por otro lado, cada realidad latinoamericana tiene sus propias peculiaridades, lo que hace interesante estudiar a Chile y Colombia. En efecto, por un lado, analizar

ble en: http://www.confecamaras.org.co/phocadownload/2019/ Cuadernos_Analisis_Economicos/Din $\%$ C3\%A1mica $\% 20 \mathrm{de} \% 20$ Creaci\%C3\%B3n\%20de\%20Empresas\%20_\%20Ene-Dic\%20 2019\%20_21012020.pdf Acesso en: 8 abr. 2020.

23 COLOMBIA. Ley 1834 DE 2019. "POR MEDIO DE LA CUAL SE FOMENTA LA ECONOMÍA CREATIVA LEY NARANJA EL CONGRESO DE COLOMBIA", Congreso de la Republica, Publicado en mayo, 2019. Disponible en: http://www. suin-juriscol.gov.co/viewDocument.asp?ruta=Leyes $/ 30030647$. Acceso en: 10 abril 2019.

24 COLOMBIA. Ley 590 DE 2000. "Por la cual se dictan disposiciones para promover el desarrollo de las micro, pequeñas y medianas empresa" Congreso de la Republica, Publicado en junio, 2000. Disponible en: http://www.suin-juriscol.gov.co/viewDocument. asp?ruta=Leyes/30030647 Acceso en: 10 abril 2019.

25 TRIBUNAL Europeo de Derechos Humanos. Sentencia de 22 de abril de 2012, caso A.C. y otros contra España. Disponible en: http://www.usc.es/export9/sites/webinstitucional/gl/institutos/ ceso/descargas/STEDH_AC-AND-OTHERS-v-SPAIN_es.pdf Acceso en: 28 de jul. 2019.

26 CORTE INTERAMERICANA DE DERECHOS HUMANOS. Sentencia de 21 de junio de 2002. Caso Hilaire, Constantine y Benjamin y otros contra Trinidad y Tobago de 2002. Disponible en: http://www.corteidh.or.cr/docs/casos/articulos/Seriec_94_esp. pdf. Acceso en: 28 jul. 2019. 
a un Estado neoliberal y a un Estado social de derecho. Por un lado, encontramos a Chile, país en que existe una serie de garantías constitucionales en favor de la libertad y autonomías sociales, y con escasa intervención del Estado. Se sigue un modelo neoliberal, instaurado en la década de los ochenta el que está casi intacto hasta nuestros días, como constata Araya Rosales y Gallardo Altaminaro ${ }^{27}$. Sin embargo, hay antecedentes de esta tradición en Chile de hace más 150 años. En efecto, en un estudio realizado por Ginsburg y Melton, que analiza más de 900 textos constitucionales, ha identificado que en el Reglamento Constitucional de Chile de $1882^{28}$, se consagra por primera vez en el mundo el derecho a establecer negocios (Right to establish a business), y que, al año 2000, 38,6\% de los países los consideran en sus Códigos Políticos. En general, se hizo para fomentar la inversión extranjera en países en vías de desarrollo ${ }^{29}$. Y, por otro, a Colombia, que indica expresamente que es un Estado Social, desde su Constitución Política de 1991, en su artículo $1^{30}$ dando relevancia al Estado en materias económicas, pero conviviendo con un sistema capitalista, como bien nos recuerda Marín Castillo y Trujillo González, según disponen los artículos 333 y 334, iniciativa privada y posibilidad dirección de la economía respectivamente ${ }^{31}$.

De ahí que es relevante realzar un estudio de derecho comparado sobre la protección constitucional de la empresa, del emprendimiento y la libre competencia. Evidentemente, los ordenamientos jurídicos escogidos son el chileno y el colombiano. Ello, dado que este método facilita dar soluciones a conflictos o situaciones comunes $^{32}$. A nivel comparativo, se abordará el estudio

27 ARAYA ROSALES, Andrés; GALLARDO ALTAMIRANO, Mauricio. El Modelo Chileno desde una ética de justicia y de igualdad de las oportunidades humanas. Polis, Chile, v. 14, n. 40, p. 265287, 2015.

28 En concreto, el artículo 222, manifestaba que, "La industria no conocerá trabas, y se irán aboliendo los impuestos sobre sus productos". CHILE. Constitución Politica del Estado de Chile, de 30 de octubre de 1822. Disponible em: https://www.leychile.cl/Navegar?idNorma=1005168 Acceso en: 22 jul. 2019.

29 GINSBURG, Tom; MELTON, James. Innovation in Constitutional Rights. Draft for presentation at NYU Workshop on Law, Economics and Politics, p. 1-29, 2012.

30 COLOMBIA. Constitución Politicade 1991. Disponibleen: http://www. suin-juriscol.gov.co/viewDocument.asp?ruta=Constitucion/1687988. Acceso en: 25 mayo 2019.

31 MARÍN CASTILLO, Juan Carlos; TRUJILLO GONZÁLEZ, José Saúl. El Estado Social de Derecho: un paradigma aún por consolidar. Revista Jurídica Derecho, Bolivia, v. 3, n. 4, p. 53-70, 2016.

32 MANCERA COTA, Adrián. Consideraciones durante el proceso comparativo. Boletín mexicano de derecho comparado, México, v. 41, de las normas constitucionales correspondientes, las de rango legal aplicables, jurisprudencia de altos tribunales en los respectivos países. Pero, además, se recurrirá a historia del derecho para interpretar y dar el verdadero sentido y alcance a las normativas, tal como se indica Ferrante, como un auxilio imprescindible para la comparación ${ }^{33}$. Finalmente, se identificarán similitudes y diferencias guiadas a una propuesta de mejoras.

Esta forma de abordar la problemática de estudio además es relevante para lo que se ha estudiado con la perspectiva del constitucionalismo y el derecho cosmopolita como un proyecto para el orden global ${ }^{34}$, a través de jurisdicción (lo que conlleva necesariamente conceder acciones y recursos judiciales a los particulares) en la protección de los derechos de la empresa, el emprendimiento y la libre competencia. Ello, dado especialmente este último "la libre competencia", beneficia no solo a las nuevas y pequeñas empresas, sino que indirectamente a todos los consumidores, es decir, al ciudadano común y corriente. En tal sentido, concuerda con otros autores, como Camacho Castro, que firma que las instituciones de control financiero pueden ser una garantía de los derechos humanos. ${ }^{35}$ Así, para el caso de la libre competencia, es declarar que, bien entendida y aplicada puede servir para un mejor disfrute de los derechos humanos, especialmente de aquellos que necesitan financiamiento.

\section{Presencia constitucional de la empresa y justiciabilidad del emprendimiento.}

\subsection{El caso colombiano. La acción de tutela.}

El concepto de personería jurídica, como herramienta para reconocer legitimación procesal y sustancial

n. 121, p. 213-243, 2008.

FERRANTE, Alfredo. Entre derecho comparado y derecho extranjero. Una aproximación a la comparación jurídica. Revista cbilena de derecho, Santiago, v. 43, n. 2, p. 601-618, 2016.

34 CAPUCIO, Camilla. National judges and courts as institutions for global economic governance. Brazilian Journal of International Law, Brasilia, v. 12, n. 2, p. 255-369, 2015.

35 CASTRO, José Miguel Camacho. El papel de las instituciones de control financiero sobre los derechos humanos en el contexto latinoamericano. Brazilian Journal of International Law, Brasilia, v. 13, n. 1, p. 156-168, 2016. 
a las empresas, ha migrado desde el derecho anglosajón para dar cabida a actores que, si bien no son orgánicos, sí son esenciales para nuestras economías de mercado. Las nuevas subjetividades y los derechos fundamentales sería el horizonte de este debate, engarzado de alguna manera con la titularidad de derechos de la naturaleza ${ }^{36}$. Estas formas de organización de personas y capitales, que giran en torno a una actividad económica, cultural e incluso política, se han convertido en parte innegable del día a día de nuestros sistemas sociales. De ese modo, el ordenamiento constitucional les reconoce no solo como sujetos habilitadas pasivamente ante imputaciones de responsabilidad por graves violaciones a los derechos humanos, sino legitimados activamente como titulares de algunas garantías y prerrogativas estatales que cristalizan su función social como empresas. En la sinexión, hay las denominadas conexiones alotéticas, como la que existe entre la sombra y el objeto que la proyecta, o las dos caras de una moneda, relación que aplicada al sistema jurídico entraña considerar como constituyente de la identidad jurídica, la existencia de deberes y su anverso los derechos.

En la Constitución colombiana la titularidad de los derechos fundamentales no es excluyente, en tanto, no solo prodiga derechos a la persona en su dimensión biológica, sino que la práctica constitucional ha evolucionado positivamente desde el derecho privado, para brindar protección constitucional reforzada a los derechos fundamentales de las personas morales. La Corte Constitucional, al analizar el concepto de persona recogido en el artículo 86 de la Constitución, que regula los mecanismos de protección de los derechos fundamentales, ha cobijado con idéntica protección, tanto a personas naturales como a personas jurídicas, ya que el enunciado normativo no establece distinción alguna entre los entes morales y las personas en su dimensión de humanidad. Desde luego que, por su propia naturaleza, esa paridad de tratamiento y protección no se aplica sin distingo a todos los derechos. Por su parte, la sentencia T-378 de 2006 reconoce que 'La persona jurídica está protegida con las garantías del Estado Social de Derecho, por lo cual, es titular de algunos derechos fundamentales ejercitables por ellas mismas; y que, en sustitución de sus miembros, también puede actuar si la

\footnotetext{
36 IORNS, Catherine. "From Rights to Responsibilities using Legal Personhood and Guardianship for Rivers (August 21, 2018). Responsability: Law and Governance for Living Well with the Earth, B Martin, L Te Aho, M Humphries-Kil (eds), Routledge, London \& New York, p. 216-239, 2019.
}

protección que se pretende incide para evitar que derechos fundamentales de las personas naturales asociadas, resulten conculcados con ocasión a la vulneración de los propios".

En ese sentido, y teniendo en cuenta el importante rol que tiene la iniciativa privada y la autonomía de la voluntad en sociedades de libre mercado, la Corte Constitucional ha reconocido ciertos derechos constitucionales fundamentales a las empresas que se relacionan con los particulares en el marco de la economía ${ }^{37}$. La Corte ha reconocido que los derechos constitucionales no son exclusivos a las personas humanas, sino que las personas jurídicas también ejercen su titularidad sobre la base que no sean aquellos "derechos inherentes a la naturaleza humana como son, entre otros, la vida, los de familia, los politicos de los ciudadanos y todos aquellos en que se involucre el reconocimiento a la dignidad humana'38.

En materia económica, la Corte Constitucional colombiana ha establecido que la Carta Política garantiza iguales condiciones a todos los participantes del mercado, pues así lo ordenan las disposiciones constitucionales de libertad de empresa y el derecho de libre asociación ${ }^{39}$. De este modo, la Corte ha reconocido que las personas jurídicas como agentes del mercado y al constituir organizaciones de personas, muchas veces pueden semejarse a las personas naturales para algunos aspectos jurídicos puntuales, salvo aquellos de naturaleza inalienable qué, como indico la Corte, "por ser privativos de la esencia de la persona natural, les son intransferibles, nunca comunicables; esto porque el contenido de esos derechos resulta totalmente incompatible con la naturaleza propia de persona ficta que son estos entes y con la función específica por la que tienen reconocimiento jurídico para actuar" ${ }^{\prime 40}$.

De modo que, la interpretación unificada de la Corte ha brindado legitimación activa a las personas jurídicas para que accedan en sede de tutela a la protección de sus derechos constitucionales; como entes autónomos que hacen parte del entorno económico de Colombia. De ese modo, la jurisprudencia constitucional ha establecido que las empresas pueden acceder, por una parte, a las garantías fundamentales que se consagran en

\footnotetext{
37 COLOMBIA. Corte Constitucional. Sentencia T 378 de 2006. M.P. Clara Inés Vargas Hernández.

38 COLOMBIA. Corte Constitucional. Sentencia T 1145 de 2005. M.P. Rodrigo Escobar Gil.

39 COLOMBIA, Corte Constitucional. Sentencia T 472 de 1996. M.P. Eduardo Cifuentes Muñoz.

40 COLOMBIA. Corte Constitucional. Sentencia T 378 de 2006. M.P. Clara Inés Vargas Hernández.
} 
la Carta de derechos de la constitución, así como a las garantías constitucionales de protección de la libertad de empresa que se protegen por conducto del derecho de la competencia.

En síntesis, la jurisprudencia Constitucional admitió sin dificultad que las personas jurídicas son titulares de algunos derechos fundamentales, y que, por ende, están habilitadas para recurrir a la acción de tutela ${ }^{41}$. Sin embargo, también estableció criterios y limitaciones al ejercicio de esta acción constitucional; pues sería insensato parificar sin reservas ni limitaciones las personas jurídicas con las personas naturales. En relación con lo anterior, la Corte Constitucional estableció que las personas jurídicas pueden ser titulares de derechos constitucionales fundamentales, por dos vías que varían en relación con las características del interés jurídico necesitado de protección constitucional. Por una parte, la vía directa, tiene como elemento característico el que la titularidad del bien jurídico protegido está en cabeza de la persona moral y no en las personas naturales asociadas a esta; por el contrario, la vía indirecta, ocurre cuando las garantías constitucionales que se busca proteger son realmente las de las personas asociadas en el ente jurídico ${ }^{42}$.

En la denominada vía directa, la Corte reconoce que las personas morales gozan de ciertos derechos constitucionales, sin necesidad que estos se refieran a los derechos de los asociados bajo la iniciativa privada que representa el ente moral. En esta variante, la Corte reconoce que la titularidad de ciertos bienes jurídicos de rango constitucional puede recaer sobre entidades no humanas; sin mediación de los derechos de los sujetos representados en estas organizaciones privadas. Por el contrario, la vía indirecta, no tiene como objetivo último la protección de la persona moral en sí misma, sino que busca proteger los derechos de los asociados que se conglomeran en torno a la persona jurídica, bien como socios o excepcionalmente colocados en la periferia de la empresa, como sería el caso de los empleados o los mismos sindicatos.

Esta variable, no concede agencia constitucional a la persona jurídica en un sentido real, sino simplemente refiere a la categoría para estructurar la protección de

\footnotetext{
${ }_{41}$ QUINCHE RAMIREZ, M. La acción de tutela elementos dogmáticos y procesales. In: VÍAS de hecho: Acción de tutela contra providencias, 9. ed. Bogotá, D.C.: Editorial Ibañez, 2012. v. 1. p. 3. 42 COLOMBIA. Corte Constitucional. Sentencia SU-448/2011. M.P. Mauricio Gonzales Cuervo.
}

otros derechos. Dos de los ejemplos principales de protección de derechos fundamentales de las personas jurídicas por vía indirecta, son los casos de amparo de los derechos de los sindicatos, en los cuales las entidades gremiales acceden a la acción de tutela con la finalidad de que se protejan los derechos de los asociados sindicales; y los casos de las Instituciones Promotoras de Salud (IPS) y las Entidades Prestadoras de Salud (EPS) que pueden acceder a la tutela en procura de garantizar los derechos de sus usuarios.

La protección de los derechos fundamentales de las personas jurídicas por la vía directa supone una protección integral a los derechos constitucionales, bajo el entendimiento de que ellas son ficciones plenas e independientes de sus asociados; que tienen vocación de ejercitar algunos derechos fundamentales; y que se desempeñan como formas jurídicas de enorme arraigo en la vida cotidiana, donde las personas entran en una actividad para complementar sus necesidades en ejercicio del valor solidaridad, y de ese modo potenciar las posibilidades individuales.

La capacidad jurídica que tiene la persona moral para ser titular de derechos; incluso de manera independiente de aquellos de las personas que representan las sociedades y las juntas directivas, es indicativo de la verdadera dimensión de la identidad de las sociedades morales en el escenario del derecho constitucional. El que exista un régimen de responsabilidad de los representantes legales respecto de las sociedades que administran, denota la doble identidad de estos entes que tienen agencia propia en las dinámicas de la economía y ante sus propios administradores.

De ese modo, la protección constitucional a la persona jurídica, se corresponde con la idea de que el derecho fundamental no solo toma en cuenta la condición humana individual o insular del sujeto, sino que el ser humano tiene siempre una dimensión gregaria, expresada constitucionalmente en el valor solidaridad, lo que apareja el reconocimiento de los derechos de los pueblos, de las etnias, de las colectividades, y aún los derechos de las futuras generaciones; como indica la Corte, "la causa ejemplar de las personas jurídicas es la misma persona humana, pero ello no indica que se identifiquen absolutamente las dos personalidades, sino más bien que la operatividad de la personas jurídicas se asimila a la de la persona natural, en todas las circunstancias en que sea razonable bacer tal asimilación - que no 
es los mismo que homologación absoluta por identificación... ${ }^{\text {«3 }}$.

Se destila de lo anterior, que la protección de los derechos fundamentales de las personas jurídicas está restringida a ciertos valores cuya protección se estima necesaria para poner dique al abuso y la arbitrariedad por parte de las entidades Estatales. En este escenario, las personas jurídicas pueden ser titulares de derechos fundamentales, pues la Corte les ha reconocido agencia respecto de ciertos derechos constitucionales que no tienen como fundamento exclusivo la condición humana. En ese sentido, de acuerdo con la Corte, "La persona jurídica no es titular de los derechos inherentes a la persona bumana, es cierto, pero sí de derechos fundamentales asimilados, por razonabilidad a ella"s4.

A los conceptos tradicional de microeconomía y macroeconomía, se han sumado recientemente las nociones de mesoeconomía y metaeconomía. Una aproximación a esta, la metaeconomía refiere a las relaciones de la economía con las demás interacciones sociales. En paralelo la mesoeconomía concierne, entre otras cosas al comportamiento de los agentes del mercado a una escala global. Entonces, el reconocimiento que la jurisprudencia de la Corte Constitucional sobre los derechos de las empresas se inscribe en el reconocimiento de su importancia, de que las relaciones económicas son también relaciones de poder que la globalización y el crecimiento de ese poder genera peligro, pero que ello no descarta la necesidad de protección de sus derechos. Justamente la libertad de mercado, la libertad de asociación y en general los valores que inspiran el liberalismo económico suponen como política la contracción del Estado a los mínimos necesarios, allanando el camino a los "particulares", abstracción esta protagonizada por las empresas y residualmente por los individuos.

Ronald Coase, a quien se atribuye la paternidad de la escuela del Análisis Económico del Derecho, recibió el premio nobel de economía por un brevísimo artículo sobre "La naturaleza de la empresa". Coase asigna mu-

\footnotetext{
43 COLOMBIA. Corte Constitucional. Sentencia T-378/2006. M.P. Clara Inés Vargas Hernández.

44 COLOMBIA. Corte Constitucional. Sentencia T-396/93. M.P. Vladimiro Naranjo Mesa. De ese modo, teniendo en cuenta que esta interpretación refiere a la cláusula general de derechos, la Corte Constitucional ha considerado que la lista de derechos de los que son titulares las personas jurídicas no es taxativa y que, por el contrario, se trata de una incardinación numerus apertus, que apareja la posibilidad de que ellas gocen de todos los derechos que razonablemente puedan ser asimilados a aquellos derechos otorgados a las personas naturales.
}

cha importancia a la empresa en la tarea de reducir los costos de transacción y es decidido partidario de que ante el peligro de abuso del Estado en tanto pudiera excederse en el ejercicio de su monopolio legítimo sobre la violencia, la mejor respuesta al costo social "era hacer nada sobre el problema en absoluto", es decir, desregular no intervenir, dejar hacer y dejar pasar. Como se intuye, ambas posturas, la importancia de la empresa y el minimalismo de la intervención del Estado, son el ambiente propicio para que las personas jurídicas tengan el protagonismo en la actividad económica.

La dimensión que han adquirido algunas empresas concebidas como personas jurídicas, que tienen proporciones incluso supra-estatales, hace insoslayable la importancia que tienen estas como protagonistas de la vida social; por lo que es urgente un sistema coherente de regulación para sus derechos y obligaciones.

En ese entorno, parece intuitivo que el ordenamiento constitucional colombiano haya reconocido, con fundamento en el derecho de igualdad, evitar que haya distinciones irrazonables entre personas naturales y jurídicas; a la hora de brindar protección jurisdiccional a los derechos constitucionales que, repítase, no son exclusivos a la persona humana. En el contexto de una Constitución que defiende a ultranza un modelo económico de libre mercado, cuyo centro es la protección de la empresa y la iniciativa privada, la Carta Política garantiza un trato igualitario por parte del Estado, que se refleja en una limitada asimilación a los derechos de las personas naturales. Como lo dijo la propia Corte: "es jurídicamente inaceptable que se le someta a la discriminación de no considerarla como titular de unas garantías que el Estado Social de Derecho ha brindado, por lógica manifestación de los fines que persigue, a toda persona, sin distinción alguna ${ }^{45}$."

Sumado a lo anterior, es menester tener presente que con promulgación de la Constitución de $1991^{46}$ ingresaron al ordenamiento jurídico colombiano una serie de acciones constitucionales ${ }^{47}$ y principios que hicieron posible la protección judicial reforzada de los derechos fundamentales. La Constitución normativa permitió consolidar la eficacia de los derechos, a través de la crea\begin{tabular}{l}
\hline 45 COLOMBIA. Corte Constitucional. Sentencia T-396/93. M.P. \\
Vladimiro Naranjo Mesa. \\
46 COLOMBIA.ConstituciónPoliticade 1991.Disponibleen:http://www. \\
suin-juriscol.gov.co/viewDocument.asp?ruta=Constitucion/1687988 \\
Acceso en: 25 may. 2019. \\
47 Como, por ejemplo, la acción de tutela, habeas corpus, habeas \\
data, entre otros.
\end{tabular} 
ción de una carta de derechos con estructura de principios, el reconocimiento de una cláusula de derechos innominados, y la concepción sobre el bloque de constitucionalidad; que han presionado, una quizás irreversible tendencia expansiva de los derechos fundamentales. Se trata de la vis expansiva de los derechos fundamentales, que, según la Academia Española de la lengua, significa ampliación de contenidos, interpretación favorable en caso de duda y limitación de las normas restrictivas. A ello añadimos potenciar la tendencia de apertura de nuevos grupos e individuos necesitados de protección, es decir la inclusión de nuevos intereses ávidos de protección. Desde luego la discusión es mucho más densa, pues llevada al límite, implicaría considerar como materia de reflexión los derechos de las futuras generaciones, de los seres sintientes, y los de la naturaleza, temas sumamente vidriosos e impropios para abordar en este concreto espacio.

De modo singular, la acción de tutela se instituyó como el recurso judicial efectivo e inmediato para la justiciabilidad de los derechos fundamentales, que refuerza y hace que la Constitución no sólo sea una Carta de aspiraciones políticas, sino el documento constitucional mediante el cual una generación concibió la escala de valores que inspira el proyecto político como legado para las generaciones futuras. Esta acción constitucional, fue creada e instituida para situar al juez en la posición de garante material de la Constitución, para así poder controlar la cotidianidad de las violaciones a los derechos humanos que aquejan a los ciudadanos; la acción de tutela instituye al juez como un actor central de la constitución, con amplia capacidad de garantizar las aspiraciones vertidas en un momento histórico en la norma superior, en este caso, la protección de los derechos fundamentales.

La acción de tutela, en un primer momento, fue instituida para proteger derechos constitucionales que se atribuían a la persona con base en su condición humana. Como indica Quinche, ${ }^{48} \mathrm{El}$ principio de dignidad, uno de los pilares de la norma constitucional corresponde con los antecedentes que fundaron el estoicismo y echa anclas en la escolástica tardía, en la ilustración, en el derecho natural racional, en las revoluciones burguesas y finalmente en la modernidad. De ese modo, la persona humana se reconoce como el eje natural de

48 CARRERA SILVA, Liliana. La acción de tutela en Colombia. Revista Ius, Puebla, v. 5, n. 27, p. 72-94, 2011. una Constitución que gira en torno a la realización de los derechos individuales y cuya legitimidad reside en la materialización normativa de este propósito.

En un auténtico orden constitucional, los valores normativos del texto superior - especialmente los atinentes a los derechos humanos - deben ser respetados y garantizados en todo momento. Los derechos constitucionales que se protegen en Colombia por vía judicial están consagrados en normas que preservan rigurosamente los valores que constituyen la esfera de inmunidades del individuo que el Estado debe respetar, y sin los cuales el hombre perdería su dignidad y su esencia. Estos, están estructurados como garantías en cabeza de las personas debido a su humanidad, y su protección fue encargada a todas las autoridades judiciales del país ${ }^{49}$. Ciertamente, los derechos fundamentales protegidos por la acción de tutela fueron concebidos para las personas naturales, pues la fundamentación de estos radica en ciertas características de la condición humana; la génesis de los derechos parte de la base del reconocimiento universal de ciertos principios que son inalienables al ser humano, y que por ende son colocados incluso a un nivel superior de la soberanía democrática.

Sin embargo, en una visión más liberal del derecho constitucional colombiano, la Corte ha precisado que las personas jurídicas "gozan de todas las garantías constitucionales para su ejercicio, entre ellas de la acción de tutela para su protección cuando les sean vulnerados o estén amenazados por la acción u omisión de una autoridad pública o de un particular'50, de ese modo, teniendo en cuenta la preponderancia del Estado Social de Derecho, la Corte Constitucional ha reconocido derechos a las personas jurídicas y ha determinado que "cuando la génesis de los derechos fundamentales no radica en la condición bumana del titular, en un Estado Social de Derecho, de ellos también son titulares las personas jurídicas",51 lo que tiene consecuencias trascendentales para la irrupción de nuevas dogmáticas en el entorno constitucional colombiano.

\footnotetext{
$49 \quad$ Los que se protegen por vía judicial y que están destinadas. Dichos valores superiores, constituyen un espacio de exclusión de la actividad estatal que las simples mayorías no pueden derogar, pues estos son los mínimos de protección de las minorías en el juego democrático.

50 COLOMBIA. Corte Constitucional. Sentencia T 378 de 2006. M.P. Clara Inés Vargas Hernández.

51 COLOMBIA. Corte Constitucional. Sentencia T 378 de 2006. M.P. Clara Inés Vargas Hernández.
} 


\subsection{El caso chileno. La acción o recurso de protección y el recurso de amparo económico.}

Algunos de los primeros antecedentes en Chile sobre la acción o recurso de protección hacen alusión a las facultades protectoras de los Tribunales de Justicia en Chile ejercida hasta $1874^{52}$. No obstante, es fundamental en la materia considerar el amparo mexicano de mediados del siglo XIX. Ello fue producto de las ideas de Manuel Crescendo García Rejón y Alcalá, quien se considera uno de los autores proyecto de Constitución del Estado de Yucatán de 1840, aprobado en 1841, que contiene el amparo como garantía constitucional en sus artículos 8, 9 y 62. A nivel federal, se incorpora en el artículo 25 del Acta de Reformas de $1847^{53}$. Luego, se incorpora el amparo en la Constitución Federal de 1857, en sus artículos 101 y 102, llegando a la actual Constitución Federal mexicana de $1917^{54}$, en sus artículos 103 y 107, desarrollado también por la ley de amparo vigente de 1936 y sus modificaciones ${ }^{55}$.

No obstante, a lo anterior, en la Constitución chilena de 1925 no se consagra el amparo o recurso de protección, y sólo desde los años 80 que se tiene presente en la estructura constitucional. Para ser más precisos, la Constitución de 1925 contiene el amparo, pero como sinónimo de habeas corpus, es decir, que resguarda la libertad de las personas y no otra serie de derechos o garantías constitucionales. Así, encontramos por primera ocasión en el Acta Constitucional $N^{\circ} 3$ de $1976^{56}$ al

52 NAVARRO BELTRÁN, Enrique. 35 años del recurso de protección notas sobre su alcance y regulación normativa. Estudios Constitucionales, Chile, v. 10, n. 2, p. 617-642, 2012.

53 Así se indicaba en el texto mexicano de 1847: Artículo 25.- Los tribunales de la Federación ampararán a cualquiera habitante de la República, en el ejercicio y conservación de los derechos que le concedan esta Constitución y las leyes constitucionales, contra todo ataque de los poderes legislativo y ejecutivo, ya de la Federación, ya de los Estados, limitándose dichos tribunales a impartir su protección en el caso particular sobre que verse el proceso, sin hacer ninguna declaración general respecto de la ley o del acto que lo motivare.

La norma citada está contenida en: MÉXICO. "Acta Constitutiva y de Reformas de 1847”. Disponible en: http://museodelasconstituciones. unam.mx/nuevaweb/wp-content/uploads/2019/02/Acta-constitutiva-y-de-reformas-1847.pdf. Acceso en: 22 jul. 2019.

54 MÉXICO. Constitución Politica de 1917, última reforma de 29 de enero de 2016. Disponible en: http://www.ordenjuridico.gob.mx/Constitucion/cn16.pdf. Acceso en: 22 jul. 2019.

55 NOGUEIRA ALCALÁ, Humberto. La acción de constitucionalidad de protección en Chile y la acción de constitucionalidad en México. Ius et Praxis, Chile, v. 16, n. 1, p. 219-286, 2010.

56 CHILE. Decreto Ley 1552, "ACTA COSTITUCIONAL Nº 3. De los derechos y deberes constitucionales". Ministerio de Justicia, publicado el amparo chileno, como sigue:

Artículo $2^{\circ}$. El que por causa de actos u omisiones arbitrarios o ilegales sufra privación, perturbación o amenaza en el legítimo ejercicio de las garantías establecidas en el artículo $1^{\circ}, \mathrm{N}^{\circ} \mathrm{s} 1,3$, inciso cuarto, $7,9,10,11,12,14,15$, inciso primero, 16, 17, 19, inciso final, 20, inciso séptimo; 22, inciso primero, y en la libertad de trabajo y el derecho a su libre elección, podrá ocurrir por sí o por cualquiera a su nombre a la Corte de Apelaciones respectiva, la que adoptará las providencias necesarias para restablecer el imperio del derecho y asegurar la debida protección del afectado, sin perjuicio de los demás derechos que pueda hacer valer ante la autoridad o los tribunales correspondientes.

La Corte Suprema dictará un auto acordado que regule la tramitación de este recurso".

Posteriormente, se aprueba la Constitución chilena de 1980, consagrando el recurso de protección. En efecto, en el actual texto, la Carta Fundamental, ${ }^{57}$ precisamente en el artículo 20 se consagra un medio procesal guiado a resguardar una serie de derechos. Es el amparo mexicano, pero con otro nombre, en Chile se denomina recurso de protección, definido por expertos, como Nogueira Alcalá como: un derecho fundamental de las personas y una acción constitucional destinada a poner en ejercicio las facultades jurisdiccionales de los tribunales de justicia (Cortes de Apelaciones) a través de un procedimiento efectivo, concentrado $y$ breve, ante actos ilegales o arbitrarios de terceros que amenacen, perturben o priven del legítimo ejercicio de los derechos expresamente mencionados en el artículo 20 de la Constitución, con el objeto de restablecer el pleno imperio del derecho y los derechos de las personas de un modo directo e inmediato $0^{58}$. Y, en concreto el artículo pertinente de la Constitución chilena manifiesta que,

Artículo 20 - El que por causa de actos u omisiones
arbitrarios o ilegales sufra privación, perturbación o
amenaza en el legítimo ejercicio de los derechos y
garantías establecidos en el artículo 19 , números $1^{\circ}$,
$2^{\circ}, 3^{\circ}$ inciso quinto, $4^{\circ}, 5^{\circ}, 6^{\circ}, 9^{\circ}$ inciso final, $11^{\circ}, 12^{\circ}$,
$13^{\circ}, 15^{\circ}, 16^{\circ}$ en lo relativo a la libertad de trabajo y
al derecho a su libre elección y libre contratación,
y a lo establecido en el inciso cuarto, $19^{\circ}, 21^{\circ}, 22^{\circ}$,
$23^{\circ}, 24^{\circ}$, y $25^{\circ}$ podrá ocurrir por sí o por cualquiera

13 de septiembre de 1976. Disponible en: https://www.leychile.cl/ Navegar?idNorma=6656 Acceso en: 22 jul. 2019.

57 CHILE. Constitución Política de la República de Chile. 16 jun. 2018. Disponible em: https:/ / www.leychile.cl/Navegar?idNorma=242302 Acceso en: 22 jul. 2019.

58 NOGUEIRA ALCALÁ, Humberto. El Recurso de Protección en el Contexto del Amparo de los Derechos Fundamentales Latinoamericano e Interamericano. Ius et Praxis, Chile, v. 13, n. 1, p. 75134, 2007. 
a su nombre, a la Corte de Apelaciones respectiva, la que adoptará de inmediato las providencias que juzgue necesarias para restablecer el imperio del derecho y asegurar la debida protección del afectado, sin perjuicio de los demás derechos que pueda hacer valer ante la autoridad o los tribunales correspondientes".

Como se puede advertir, sirve ante casos de actos u omisiones, ya sean estas ilegales o arbitrarios, de privaciones, perturbaciones o amenazas en el legitimo ejercicio de determinados derechos, $\mathrm{y}$, justamente protege a los relacionados con el emprendimiento, de forma directa y aquellos que lo complementan. Así, se considera expresamente al artículo $19 \mathrm{~N}^{\circ} 21$, es decir, el derecho a desarrollar cualquiera actividad económica que no sea contraria a la moral, al orden público o a la seguridad nacional, respetando las normas legales que la regulen.

Pero, además, el inciso segundo del mencionado numeral 21 indica que "el Estado y sus organismos podrán desarrollar actividades empresariales o participar en ellas sólo si una ley de quórum calificado los autoriza. En tal caso, esas actividades estarán sometidas a la legislación común aplicable a los particulares, sin perjuicio de las excepciones que por motivos justificados establezca la ley, la que deberá ser, asimismo, de quórum calificado". Es una norma que surge precisamente en los años ochenta, en que lo explica de forma muy asertiva Chonchol ${ }^{59}$, es decir, no es casualidad la época de incorporación de la norma al texto constitucional. En efecto, da justo con periodos históricos donde toman fuerza el mercado y la empresa privada, resurgiendo el liberalismo económico, particularmente en Reino Unido y Estados Unidos con reformas radicales tendientes a reducir la intervención del Estado en la economía, que se ha extendido por todo el mundo, también llegando a Chile y a su normativa constitucional y legal.

Así, para el caso chileno, el Estado puede actuar en materia empresarial, siempre y cuando una ley de quórum calificado se lo autorice. Al obtener una ley de dicha naturaleza, se crea una empresa del Estado, con personalidad jurídica propia, descentralizada, pero formando parte de la Administración del Estado ${ }^{60}$ en cuanto a su supervigilancia por el Ministerio respectivo. Es decir, el

\footnotetext{
59 CHONCHOL, Jacques. Impacto de la globalización en las sociedades latino-americanas: ¿qué hacer frente a ello?. Estudos Avançados, Brasil, v. 12, n. 34, p. 163-186, 1998.

60 LATORRE VIVAR, Patricio. Las sociedades estatales en el ordenamiento jurídico chileno: Naturaleza, límites y control de sus actividades. Revista de Derecho de la Pontificia Universidad Católica de Valparaiso, Chile, n. 30, p. 223-240, 2008.
}

Estado no tiene vetado actuar en materia empresarial, sin embargo, le es más difícil porque necesita un quórum del 50\% más uno de los diputados y senadores en ejercicio, conforme al artículo 66 que regula los tipos de leyes, formación y su aprobación. Un ejemplo de empresa estatal en Chile es la Corporación Nacional del Cobre de Chile, más conocida como CODELCO ${ }^{61}$.

Lo anterior también está relacionado con lo que se ha denominado principio de subsidiariedad del Estado, es decir, que el Estado intervenga "en subsidio" a los particulares y no subsidiando inmediatamente. Muy bien ha resumido la dicotomía que tiene este principio, Loo Gutiérrez, quien indica se ha dicho, por un lado, y a favor, que es una fórmula que resuelve los problemas del Estado, restituyéndole sus funciones y su ámbito de acción propio, por otro, negativamente, es condenado dar lugar al egoísmo y la avaricia del ser humano como motores de la vida social ${ }^{62}$. También está relacionado con el principio de autonomías sociales, como puede desprenderse de la Encíclica papal Quadraggesimo Anno, de 1931, de Pío XI: "como no es lícito quitar a los individuos lo que ellos pueden realizar con sus propias fuerzas o industrias para confiarlo a la comunidad, de la misma manera es injusto,... entregar a una sociedad mayor y más elevada aquellas cosas que las comunidades menores e inferiores pueden

${ }_{61}$ A modo de ejemplo, es menester citar el artículo 1 del Decreto Ley 1350 de 1976, que consagra que: Artículo 1. Créase, con la denominación de Corporación Nacional del Cobre de Chile, que podrá usar como denominación abreviada la expresión CODELCO o CODELCO-CHILE, una empresa del Estado, minera, industrial y comercial, con personalidad jurídica y patrimonio propio, domiciliada en la comuna de Santiago, de duración indefinida, sometida a la fiscalización de la Superintendencia de Valores y Seguros en los mismos términos que las sociedades anónimas abiertas, sin perjuicio de lo dispuesto en el decreto ley $N^{\circ} 1.349$, de 1976, que crea la Comisión Chilena del Cobre, y que se relacionará con el Gobierno a través del Ministerio de Minería. En el presente decreto ley se la denominará también la "EMPRESA".

CODELCO se regirá por las normas de la presente ley y por la de sus Estatutos y, en lo no previsto en ellas y en cuanto fuere compatible y no se oponga con lo dispuesto en dichas normas, por las normas que rigen a las sociedades anónimas abiertas y por la legislación común, en lo que le sea aplicable.

La norma citada está contenida en: CHILE. Decreto Ley 1350, "CREA LA CORPORACIÓN NACIONAL DEL COBRE DE CHILE”. Ministerio de Minería, publicado el 28 de febrero de 1976, 9 ene. 2014, por modificación de la Ley 20720. Disponible en: https://www.leychile.cl/Navegar?idNorma=6578\&idParte Acceso en: 22 jul. 2019.

62 LOO GUTIÉRREZ, Martín. La disciplina constitucional del principio de subsidiariedad en Italia y Chile. Revista de Derecho de la Pontificia Universidad Católica de Valparaíso, Chile, n. 33, p. 391-426, 2009. 
hacer..." 63 . Sería entonces la sociedad mayor el Estado y los particulares la sociedad menor. Esto tiene sentido por regla general, pero siempre hay excepciones, sino sólo recordar las fortunas de empresas multinacionales, en que su fortuna puede ser igual o mayor a ciertos Estados.

Además, se consideran otros numerales que consagran derechos que complementan al emprendimiento, es decir, aquellos que sirven para que este sea efectivo. En efecto, así, encontramos en la Constitución chilena ${ }^{64}$, al artículo $19 \mathrm{~N}^{\circ} 15$, derecho de asociación; al artículo $19 \mathrm{~N}^{\circ} 22$, derecho a no ser discriminado arbitrariamente en materia económica por parte del Estado; al artículo $19 \mathrm{~N}^{\circ} 23$, la libertad para adquirir el dominio de toda clase de bienes, excepto los que la naturaleza ha hecho comunes o que deben pertenecer a la Nación; al artículo $19 \mathrm{~N}^{\circ} 24$, derecho de propiedad privada. Estos derechos y libertades son necesarios para un efectivo desarrollo del emprendimiento. Así, al dar la posibilidad de crear empresas, creándose personas jurídicas distintas a los de sus titulares, fomenta la actividad y aligera los riesgos en el patrimonio personal; al no ser discriminado arbitrariamente en materia económica, no debiera haber impuestos excesivos no trabas caprichosas a ciertas actividades; al poder adquirir la propiedad, se podrá disfrutar de las ganancias del emprendimiento; y, al protegerse la propiedad privada, aquellas ganancias podrán utilizarse en bienes para así capitalizar. Todos estos derechos y libertades también coinciden, a ojos del constitucionalista, Arturo Fermandois Vöhringer ${ }^{65}$, con los elementos del Orden Público Económico chileno. En efecto, estos serían, el principio de la libertad económica; el principio de subsidiariedad económica del Estado; el principio del derecho de propiedad privada; el principio de la disciplina del gasto fiscal; el principio de política monetaria independiente; el principio de la

63 VATICANO. PÍO XI. Carta Encíclica Quadragesimo anno. "SOBRE LA RESTAURACIÓN DEL ORDEN SOCIAL EN PERFECTA CONFORMIDAD CON LA LEY EVANGÉLICA AL CELEBRARSE EL $40^{\circ}$ ANIVERSARIO DE LA ENCÍCLICA "RERUM NOVARUM" DE LEÓN XIII", dada en Roma, a 15 de mayo de 1931. Disponible en: http://w2.vatican.va/content/piusxi/es/encyclicals/documents/hf_p-xi_enc_19310515_quadragesimo-anno.html Acceso en: 22 jul. 2019.

64 CHILE. Constitución Política de la República de Chile.16 jun. 2018. Disponible em: https://www.leychile.cl/Navegar?idNorma $=242302$. Acceso en: 22 jul. 2019.

65 FERMANDOIS VÖHRINGER, Arturo. El Orden Público Económico bajo la Constitución de 1980. Ius Publicum, Chile, n. 4, p. $63-78,2000$. reserva legal de la regulación económica; y, el principio de la revisión judicial económica.

Además, es menester tener presente que la mayoría de estos derechos y libertades son parte del bloque de constitucionalidad chileno, no sólo por estar contenidos en la Carta Fundamental, sino que además por Tratados Internacionales sobre Derechos Humanos, ratificados por Chile y vigentes ${ }^{66}$, conforme al artículo 5 de la Constitución Política de Chile. En efecto, el Pacto de San José de Costa Rica ${ }^{67}$, considera en el artículo 3 al derecho al reconocimiento a la personalidad jurídica, en el artículo 16 a la libertad de asociación, en el artículo 21 al derecho a la propiedad privada. Y, en el Pacto Internacional de Derechos Civiles y Políticos ${ }^{68}$, en el artículo 16, el reconocimiento a la personalidad jurídica, en el artículo 22 al derecho de asociación.

Pero, además, no es sólo declarar derechos, estos deben tener una acción o recurso para que estos sean efectivos. Siguiendo la arista internacional, el Pacto de San José de Costa Rica consagra que:

\section{Artículo 25. Protección Judicial}

1. Toda persona tiene derecho a un recurso sencillo y rápido o a cualquier otro recurso efectivo ante los jueces o tribunales competentes, que la ampare contra actos que violen sus derechos fundamentales reconocidos por la Constitución, la ley o la presente Convención, aun cuando tal violación sea cometida por personas que actúen en ejercicio de sus funciones oficiales.

2. Los Estados Partes se comprometen:

a) a garantizar que la autoridad competente prevista por el sistema legal del Estado decidirá sobre los derechos de toda persona que interponga tal recurso;

b) a desarrollar las posibilidades de recurso judicial, y

${ }^{66}$ DÍAZ FUENZALIDA, Juan Pablo. ¿Son parte del bloque de constitucionalidad los principales tratados internacionales de derechos humanos de la ONU en Chile? Del texto positivo a la aplicación en tribunales de justicia. Revista Brasileira de Políticas Públicas, Brasilia, v. 9, n. 1, p. 153-171, 2019.

67 ORGANIZACIÓN DE LOS ESTADOS AMERICANOS. Convención Americana sobre Derechos Humanos, suscrita en la Conferencia especializada interamericana sobre Derechos Humanos (B-32). San José de Costa Rica, del 7 al 22 de noviembre de 1969. Disponible en: https://www.oas.org/dil/esp/tratados_b-32_convencion_americana_ sobre_derechos_humanos.htm. Acceso en: 22 jul. 2019.

68 NACIONES UNIDAS. Pacto Internacional de Derechos Civiles y Políticos, Resolución 2200 A (XXI), de 16 de diciembre de 1966. Disponible em: https://treaties.un.org/doc/Treaties/1976/03/19760323\%20 06-17\%20AM/Ch_IV_04.pdf. Acceso en: 22 jul. 2019. 
c) a garantizar el cumplimiento, por las autoridades competentes, de toda decisión en que se haya estimado procedente el recurso".

$\mathrm{Y}$, a su turno, el Pacto Internacional de Derechos Civiles y Políticos ${ }^{69}$, consagra que:

Art. 3.a. del Pacto Internacional de Derechos Civiles y Políticos.

Cada uno de los Estados Partes en el presente Pacto se compromete a garantizar que:

a) Toda persona cuyos derechos o libertades reconocidos en el presente Pacto hayan sido violados podrá interponer un recurso efectivo, aun cuando tal violación hubiera sido cometida por personas que actuaban en ejercicio de sus funciones oficiales".

Es decir, los Estados, incluyendo a Chile se comprometen a incorporar en su ordenamiento jurídico nacional, acciones o recursos que sirvan para hacer efectivos los derechos. Así, el recurso de protección encuadra como una herramienta jurídica que resguarda los derechos anteriormente expresados con el emprendimiento. Y, en cuanto a la tramitación del recurso, es menester tener presente, además de la Constitución, al Auto Acordado que ha emitido la Excelentísima Corte Suprema y sus respectivas modificaciones ${ }^{70}$. No obstante, a que la tramitación de un procedimiento debiera estar consagrada en una norma de rango legal, y, no en un Auto Acordado, afectado el principio de legalidad en materia procesal, como han indicado, autores como Andrés Bordalí Salamanca ${ }^{71}$, es quizás por la inactividad o falta de acuerdo del legislador chileno crear una ley de procedimiento respecto de la acción o recurso de protección que la tramitación y fallo de este, que se regula

\footnotetext{
69 NACIONES UNIDAS. Pacto Internacional de Derechos Civiles y Politicos, Resolución 2200 A (XXI), de 16 de diciembre de 1966. Disponible em: https://treaties.un.org/doc/Treaties/1976/03/19760323\%20 06-17\%20AM/Ch_IV_04.pdf. Acceso en: 22 jul. 2019.

70 CHILE. Excelentísima Corte Suprema. Auto Acordado 94-2015. “TEXTO REFUNDIDO DEL AUTO ACORDADO SOBRE TRAMITACIÓN Y FALLO DEL RECURSO DE PROTECCIÓN DE LAS GARANTÍAS CONSTITUCIONALES", publicado el 28 de agosto de 2015, última versión de 5 de octubre de 2018, por modificación del Auto Acordado 173 de 5 de octubre de 2018. Disponible en: https://www.leychile.cl/Navegar?idNorma=1080916 Acceso en: 22 jul. 2019.

71 BORDALÍ SALAMANCA, Andrés. El recurso de protección entre exigencias de urgencia y seguridad jurídica. Revista de Derecho (Valdivia), Chile, v. 19, n. 2, p. 205-228, 2006.
}

por dicha norma de la Corte. Entre estas, se declaran expresamente asuntos relevantes como el plazo de interposición del recurso, que es de 30 días (artículo 1), por escrito (artículo 2), solicitar informes, que es como una especie de contestación de quienes pudiesen haber vulnerado un derecho (artículo 3), la alegatos o autos en relación en la respectiva Corte de Apelaciones (artículo 3), posibilidad de apelar la sentencia en el plazo de 5 días (artículo 6), entre otros aspectos de tramitación.

Así, un caso interesante que traer a colación al respecto es un recurso de protección deducido por una S.A. en contra de una Municipalidad en el año 2017 y resuelto el 2018. En efecto, la Excelentísima Corte Suprema confirma una sentencia ${ }^{72}$, que acoge el recurso de protección, considerando vulnerados los números 21, 22 y 24 de una empresa por un acto administrativo. En concreto, se determinó que,

\begin{abstract}
"la resolución recurrida conculca las garantías constitucionales que estima afectadas la recurrente, pues se le impide desarrollar sus actividades económicas y perturba su derecho de propiedad sobre los productos provenientes de las mismas; pues se le impide conocer los requisitos que estima necesarios la recurrida para el desarrollo de aquéllas, específicamente en lo relativo a la patente comercial y en cuya ausencia, se fundó en su oportunidad la clausura del establecimiento de canteras Lonco S.A.; por lo que la acción intentada será acogida ${ }^{73}$ ".
\end{abstract}

De esta manera, se evidencia que el recurso de protección, guiado a proteger una serie de garantías constitucionales, en principio, creado para personas naturales, está contemplado en resguardar derechos y libertades, ya sean personas físicas o jurídicas las afectadas.

Además del recurso o acción de protección, el derecho a desarrollar cualquier actividad económica se resguarda con el denominado recurso de amparo económico. Es una norma curiosa desde diversos puntos de vista. Por ejemplo, es una ley de artículo único y se publica en el Diario Oficial de Chile justo a un día antes de que asumiera como Presidente Patricio Aylwin, primer Jefe de Estado de vuelta a la Democracia el 11 de marzo de 1990. Sin embargo, a toda la crítica que pudiera haber en ese sentido, lo cierto es que la norma aún

72 CHILE. Excelentísima Corte Suprema. Rol No 11.957-2018. Sentencia de 05 de mayo de 2018.

73 CHILE. Ilustrísima Corte de Apelaciones de Concepción. Rol $N^{\circ}$ 7.178-2017. Sentencia de 11 de mayo de 2018. 
sigue vigente al 2019, sin modificaciones. Así entonces, se consagra en la Ley 18.971, de 10 de marzo de 1990, ${ }^{74}$ el recurso de amparo económico.

En efecto, hay ciertas diferencias respecto de la acción o recurso de protección, entre otras destaca que: el actor no necesitará tener interés actual en los hechos denunciados; el plazo de interposición es de seis meses contados desde que se hubiere producido la infracción; el procedimiento que se sigue es el del recurso de amparo (el del habeas corpus chileno); se presenta ante la Corte de Apelaciones respectiva; posibilidad de doble instancia; obligación del tribunal de investigar la infracción denunciada, y, en caso de no ser apelada la sentencia de la Corte de Apelaciones, deberá ser consultada por la Corte Suprema.

Ahora bien, sin perjuicio que existan las acciones o recursos, la interpretación y aplicación ha sido disímil, tal como explica en un comentario de jurisprudencia el actual señor Ministro del Tribunal Constitucional de Chile, Dr. Domingo Hernández Emparanza ${ }^{75}$. En efecto, ha existido una primera etapa de interpretación restrictiva, resguardándose sólo el inciso segundo del artículo 19 de la Constitución, es decir, sólo ante exceso o desbordes del Estado empresario, en concreto cuando no había autorización de ley de quórum calificado para actuar (años 1990-1995). Luego, varía la jurisprudencia a una interpretación amplia, vale decir, resguardándose ambos incisos del artículo 19 numeral 21, inclusive resguardando el Derecho cuando es vulnerado por el Estado o inclusive un privado (años 1995-2008). Y, posteriormente, desde el caso González Illanes con Municipalidad de Santiago, en 2009, ha habido sentencias en ambos sentidos.

Un caso reciente, de 2019, considera la tesis de que el recurso de amparo económico protege ambos incisos del artículo $19 \mathrm{~N}^{\circ} 21$, y, además, no sólo en contra del Estado. Así, se presenta un recurso de amparo económico por una persona natural en contra de una S.A., es decir, privados contra privados. En efecto, la Excelentísima Corte Suprema resolvió que la Sociedad Anónima recurrida no podrá informar como deudora morosa a la

74 CHILE. Ley 18971, "ESTABLECE RECURSO ESPECIAL QUE INDICA". Ministerio de Economía, Fomento y Reconstrucción, publicada el 10 de marzo de 1990. Disponible en: https:// www.leychile.cl/Navegar?idNorma=30339. Acceso en: 22 jul. 2019.

75 HERNÁNDEZ EMPARANZA, Domingo. El recurso de amparo económico: una tendencia jurisprudencial peligrosamente reduccionista. Estudios Constitucionales, Chile, v. 8, n. 1, p. 443-466, 2010. persona natural, sea a la Superintendencia de Bancos e Instituciones Financieras o a otras instituciones. La ratio del caso fue que sobre las deudas morosas se había pactado una serie de convenios de pago (en estricto rigor operó una novación y, por tanto, ya no hay mora, sino que existe una deuda nueva), por lo que aparecer en el sistema financiero como morosa, en palabras textuales del máximo tribunal "supone para aquélla la imposibilidad o, al menos, un obstáculo considerable, para acceder al crédito, pues, en esas condiciones, las instituciones que integran el sistema financiero difícilmente le prestarán dinero" ${ }^{\text {776 }}$. El caso es relevante, pues confirma el criterio de la jurisprudencia en favor de la defensa del artículo $19^{\circ} \mathrm{N}^{\circ} 21$ completo, pero además suma que el recurso de amparo económico procede también entre particulares.

Por otro lado, es menester complementar tanto el recurso o acción del primer punto y la tratada en este acápite, con lo siguiente, el derecho a emprender no es un derecho absoluto, también tiene limitaciones. Es así como se ha evidenciado en la jurisprudencia chilena y constatado por la doctrina. En efecto, Julio Alvear Téllez $z^{77}$, ha manifestado que, en muchas ocasiones existe denegatoria de las acciones o recursos de amparo económico que ha sido por causa imputable a los denunciantes, que no logran apreciar ni conjugar suficientemente la actividad económica, con la legislación o normativa reguladora. En efecto, los derechos y libertades fundamentales están en constante contraposición, y, por ejemplo, si se crea una empresa y, esta contamina más allá de lo permitido, en el caso chileno vulnerará el derecho de vivir en un medio ambiente libre de contaminación, que también está consagrado en la Constitución ${ }^{78}$, en particular en el artículo $19 \mathrm{~N}^{\circ} 8$, y, es resguardado por el recurso o acción de protección.

76 CHILE. Excelentísima Corte Suprema. Rol No 4.244-2019. Sentencia de 28 de febrero de 2019.

77 ALVEAR TÉLLEZ, Julio. La jurisprudencia del amparo económico los tres grandes déficits de la última década. Estudios Constitucionales, Chile, v. 11, n. 1, p. 167-220, 2013.

78 CHILE. Constitución Política de la República de Chile. 16 jun. 2018. Disponible em: https://www.leychile.cl/Navegar?idNorma=242302. Acceso en: 22 jul. 2019. 


\section{Derecho constitucional a la libre competencia y su justiciabilidad}

\subsection{El caso colombiano: constitucionalidad e institucionalidad para su protección}

$\mathrm{Al}$ margen de las garantías constitucionales que la Corte Constitucional Colombiana ha reconocido en favor de las personas jurídicas; según las cuales estas últimas cuentan con legitimación activa para el ejercicio de la acción constitucional de tutela, la Constitución Colombiana ha reconocido otros derechos constitucionales no fundamentales a favor de las empresas; particularmente el derecho a la libre competencia económica. Las acciones pertenecientes al régimen de libre competencia, si bien no son acciones constitucionales en rigor como la tutela, representan mecanismos legales que protegen bienes jurídicos de rango constitucional.

A través de los artículos 333 y 334, la Constitución ha definido a la libre competencia económica como un derecho que asiste a todos y que también acarrea responsabilidades. En esa medida, la constitución ha introducido un modelo de economía social de mercado, que propende por mantener el balance en un sistema que, por una parte, garantiza los derechos y, por otra parte, promueve la libertad económica. Desde esta visión, la libre competencia es un derecho que, como dijo la Corte, se concibe "como un derecho individual y a la vez colectivo (articulo 88 de la Constitución), cuya finalidad es alcanzar un estado de competencia real, libre y no falseada, que permita la obtención del lucro individual para el empresario, a la vez que genera beneficios para el consumidor con bienes y servicios de mejor calidad, con mayores garantías y a un precio real y justo"'

Según la norma superior, el Estado debe garantizar el cumplimiento del principio constitucional de libre competencia, en la medida que la satisfacción de este fin constitucional conduce a la protección de todo el sistema de libre mercado, mientras previene contra las conductas monopólicas, los actos de competencia desleal y los acuerdos de precios; que en sí mismos son fines constitucionales que conducen al efectivo desarrollo de la libertad de empresa. Como indica la Corte, "El Derecho a la Libre Competencia Económica implica dos aspectos fundamentales: de una parte, garantiza la liber-

COLOMBIA. Corte Constitucional. Sentencia T-830/10. M.P. Luis Ernesto Vargas Silva. tad de los competidores para concurrir al mercado en busca de una clientela; y de la otra implica la libertad de los consumidores para escoger y adquirir en el mercado, bienes y servicios que se ofrezcan en condiciones de competencia" $"$.

Si bien es cierto que el modelo económico de libre mercado adoptado por Colombia, parte de la premisa de una mínima intervención por parte del Estado en la economía, esto no ocurre en perjuicio de las reglas de protección de la libre competencia, que son normas de orden público y garantizan la sostenibilidad del propio sistema económico. Las autoridades de protección del régimen de libre competencia deben ser entidades técnicas e independientes que cuenten con la capacidad de garantizar la probidad del sistema económico pues, como indica la Corte, "Ante la comisión de una práctica que altere las condiciones del mercado y que afecta cualquiera de los supuestos ya señalados, es obligación del Estado intervenir para sancionar dichas prácticas y, por ende, restablecer las condiciones iniciales del mercado ${ }^{81}$.

Como lo ha indicado la propia Superintendencia de Industria y Comercio, el Estado tiene el deber de proteger el adecuado funcionamiento de la economía de mercado, y, por ende, es el principal llamado a asegurar condiciones adecuadas para la libre competencia y el "responsable de eliminar las barreras de acceso al mercado y censurar las prácticas restrictivas de la competencia, como el abuso de la posición dominante o la creación de monopolios" ${ }^{\prime 2}$. En ese sentido, la Ley 1340 de 2009 que desarrolla el régimen de protección a la libre competencia en Colombia, en su artículo $6^{\circ}$, designa como Autoridad Nacional de Protección de la Competencia a la Superintendencia de Industria y Comercio, "quien conocerá en forma privativa de las investigaciones administrativas, impondrá las multas y adoptará las demás decisiones administrativas por infracción a las disposiciones sobre protección de la competencia, así como en relación con la vigilancia administrativa del cumplimiento de las disposiciones sobre competencia

80 COLOMBIA. Corte Constitucional. Sentencia C-535 del 97. M.P. Eduardo Cifuentes Muñoz

81 COLOMBIA. Corte Constitucional. Sentencia C-263/11. M.P. Jorge Ignacio Pretelt Chaljub.

82 COLOMBIA. Comisión de Regulación de Comunicaciones. Caso Tigoune del 05 de octubre De 2016. Disponible en: https://www. crcom.gov.co/recursos_user/2016/Actividades_regulatorias / merc_moviles/coment2/2016-LA_PROTECCION_CONSTITUCIONAL_DE_LA_LIBRE_COMPETENCIA.pdf. Acceso en: 01 ago. 2019. 
desleal". De ese modo, la llamada SIC, se ha convertido en una institución que es fundamental para la protección de la economía de libre mercado, que ha sido reconocida por alguna jurisprudencia como una garantía supra individual. ${ }^{83}$

Las facultades que tiene la Superintendencia de declarar la violación al régimen de libre competencia y de ordenar el resarcimiento de daños por las conductas desleales de los competidores conducen a la protección de bienes jurídicos que encuentran su asidero en la constitución, particularmente en el artículo 333 de la Carta $^{84}$. La legislación que desarrolla estas normas constitucionales refleja el claro propósito de proteger estos derechos que se reconocen como constitucionales desde una faceta jurisdiccional y otra faceta administrativa.

Esta normativa, busca que el mercado se desarrolle dentro del mandato constitucional de libre competencia y asegurar de ese modo la garantía de la libertad de empresa y el respeto por los derechos de los consumidores. Como se verá, el régimen de protección a la libre competencia es un mecanismo cuasi-constitucional que se manifiesta en dos etapas que conllevan a la activación de la habilitación constitucional que tiene el Estado para hacer efectivo dicho mandato, a través de la intervención en la economía. Esta normativa, así mismo, asigna al Estado "no sólo la facultad sino la obligación de intervenir en la economía con el fin de remediar las fallas del mercado y promover el desarrollo económico y social" 85 .

Por una parte, la fase jurisdiccional de la protección a la libre competencia en Colombia, trata de un proceso que busca individualizar una responsabilidad en cabeza de quienes con sus conductas lesionen los bienes jurídicos tutelados por el principio constitucional

\footnotetext{
83 El Régimen Legal de Competencia consagró las pautas frente a la prohibición de prácticas restrictivas de la competencia y al abuso de la posición dominante en el mercado, a través de la expedición de la Ley 155 de 1959 y en el Decreto 2153 de 1992. Además, en el Decreto 3466 de 1982 encontramos las disposiciones y estamentos sobre protección al consumidor, en el Decreto 150 de 1993 encontramos la regulación jurídica respecto a los derechos antidumping y compensatorios, en la Ley 256 de 1996 se hace alusión a las Normas sobre prohibición de las conductas de competencia desleal, y finalmente, la Ley 1340 de 2009 donde se encuentran contenidas las Normas en materia de la protección de la competencia.

84 COLOMBIA. Corte Constitucional. Sentencia T-830/10. M.P. Luis Ernesto Vargas Silva; COLOMBIA. Corte Constitucional. C-836 de 2001. M.P. Rodrigo Escobar Gil

85 COLOMBIA. Corte Constitucional. Sentencia C-263/11. M.P. Jorge Ignacio Pretelt Chaljub.
}

del libre mercado, como indica la Corte, "se trata de un proceso jurisdiccional que se lleva a cabo en contra de quienes han cometido un acto o una conducta que lesione los intereses de los que son sujetos de protección de la norma" ${ }^{86}$. Por otra parte, "En lo atinente con la aplicación pública del derecho de la competencia, se trata de procesos eminentemente administrativos sancionatorios en donde lo que se busca es garantizar el cumplimiento de los fines propuestos en el texto constitucional, es decir, protección al consumidor, eficiencia económica, libertad de empresa y libre competencia económica" ${ }^{" 87}$.

De ese modo, el derecho de la competencia tiene una base jurisdiccional y una base administrativo-sancionatoria que tienen como objeto común el propósito constitucional de garantizar el cumplimiento del llamado derecho de la competencia, y en particular la protección de los bienes jurídicos supra-individuales que se tutelan con este; es decir, "la protección al consumidor, eficiencia económica, libertad de empresa y libre competencia económica" ${ }^{88}$.

Dado que las garantías constitucionales propias de la libertad de empresa encuentran su verdadero sentido, cuando se les comprende dentro del marco de protección del interés social de las personas que concurren en el mercado, la cláusula general de competencia habilita diferentes mecanismos para sancionar las conductas destinadas a lesionar los bienes jurídicos protegidos por el derecho de la competencia ${ }^{89}$.Estas conductas, se dividen en acuerdos anticompetitivos, actos anticompetitivos, abuso de posición de dominio e integraciones empresariales.

La cláusula general de competencia permite al Estado intervenir en la economía, con el fin de proteger los bienes y valores constitucionales que se concretizan en las operaciones de intercambio de bienes y servicios ${ }^{90}$.

86 COLOMBIA. Corte Constitucional. C-537 2010. M.P Juan Carlos Henao Pérez.

87 BULLARD, Alfredo. La prohibición imposible. ¿Cómo tratar a los monopolios en la Constitución? Revista de la Facultad de Derecho (PUCP), Perú, n. 56, pp, 759-793, 2003.

88 OSSA BOCANEGRA, Camilo Ernesto. Fundamentos de la aplicación pública del derecho de la competencia en Colombia. Revista Facultad de Derecho y Ciencias Políticas, Medellín, v. 44, n. 120, p. 181-219, 2014

89 OSSA BOCANEGRA, Camilo Ernesto. Fundamentos de la aplicación pública del derecho de la competencia en Colombia. Revista Facultad de Derecho y Ciencias Políticas, Medellín, v. 44, n. 120, p. 181-219, 2014.

90 COLOMBIA. Corte Constitucional. Sentencia C-228 de 24 de 
En efecto, la libertad económica se erige como "principio constitucional esencial que a su vez condensa los derechos a la libre competencia, el de libertad de empresa, y la prohibición de monopolios"91.

El panorama competitivo que compone la libertad económica lo integran diferentes dimensiones que se expresan según sea su ámbito de aplicación; según fuere individual o colectiva. Por una parte, la dimensión individual, es aquella en la que los sujetos se constituyen como beneficiarios "de un régimen competitivo y eficiente pues de tal forma se garantiza la posibilidad de elegir libremente entre varios competidores lo que redunda en una mayor calidad y mejores tarifas por los servicios recibidos". Por el contrario, la dimensión colectiva está dirigida a "proteger los derechos e intereses de los consumidores y usuarios de bienes servicios", y a su vez el "beneficio de disfrutar una economía con condiciones competitivas para los empresarios" ${ }^{\prime 2}$. En este orden de ideas, "esta libertad también es una garantía para los consumidores, quienes en virtud de ella pueden contratar con quien ofrezca las mejores condiciones dentro del marco de la ley y se benefician de las ventajas de la pluralidad de oferentes en términos de precio y calidad de los bienes y servicios, entre otros" ${ }^{\prime 9}$.

En suma, el marco normativo de la constitución de 1991, reconoce un horizonte de titulares de derechos constitucionales más amplio que aquel de la persona humana, y por ende ha reconocido una serie de garantías que permiten a las personas jurídicas, como entidades que se desarrollan en la vida social; dentro de la economía de libre mercado y el Estado Social de Derecho, ejercer ciertas garantías que por una parte les favorece

marzo 2010. M.P. Luis Ernesto Vargas Silva.

91 COLOMBIA. Comisión de Regulación de Comunicaciones. Caso Tigoune del 05 de octubre De 2016. Disponible en: https://www. crcom.gov.co/recursos_user/2016/Actividades_regulatorias/ merc_moviles/coment2/2016-LA_PROTECCION_CONSTITUCIONAL_DE_LA_LIBRE_COMPETENCIA.pdf. Acceso en: 01 ago. 2019; sobre las prácticas monopólicas en el régimen comparado de la competencia: FERRAZ, Daniel Amin. Horizontal agreements, vertical agreements and European and north American jurisprudence on the matter. Brazilian Journal of International Law, Brasilia, v. 9, n. 2, p. 150-160, 2012.

92 COLOMBIA. Corte Constitucional. Sentencia C-535 del 97. M.P. Eduardo Cifuentes Muñoz.

93 COLOMBIA. Comisión de Regulación de Comunicaciones. Caso Tigoune del 05 de octubre De 2016. Disponible en: https://www. crcom.gov.co/recursos_user/2016/Actividades_regulatorias / merc_moviles/coment2/2016-LA_PROTECCION_CONSTITUCIONAL_DE_LA_LIBRE_COMPETENCIA.pdf. Acceso en: 01 ago. 2019. como particulares, y por otra parte, propende por la realización del objetivo constitucional de garantizar la libertad de empresa; esencial en un sistema en un sistema que reconoce el libre mercado, atizado por la función social de la propiedad ${ }^{94}$.

En el país sudamericano, la constitución política de 1991 le asigna una función social y ecológica a la propiedad a través del artículo 58. En línea con los postulados de Duguit ${ }^{95}$, la Corte Constitucional Colombiana estableció que "el derecho de dominio deviene función social, lo que significa que el propietario no es un sujeto privilegiado, como hasta el momento lo había sido"96, sino más que todo un sujeto que tiene obligaciones ante la sociedad, y de cara al ejercicio responsables de la propiedad.

\subsection{El caso chileno ¿Constitucionalidad o legalidad para su protección? Acciones constitucionales y el Tribunal de Defensa de la Libre Competencia.}

Si bien el derecho a desarrollar cualquier actividad económica está expresamente contemplado en la Constitución chilena como una garantía, como se ha explicado (artículo $19 \mathrm{~N}^{\circ} 21$ ), y, que está resguardada por la acción o recurso de protección y por el recurso de amparo económico, lo cierto es que el desarrollo normativo es de rango legal. No obstante, a que no haya una norma que excluya estas acciones o recursos, al ser estas excepcionales, ante casos sobre atentados a la libre competencia, es difícil que las Cortes se hagan cargo por dichas vías. Ello no implica que no serán atendidas en tribunales, sino existen otros caminos procesales a seguir, salvo alguna excepcionalidad y urgencia del caso que tenga mérito suficiente o haga infectivo los otros procedimientos.

En efecto, en la institucionalidad chilena, se crea el Tribunal de Defensa de la Libre Competencia, en el año 2003, en periodo en que fue Presidente de la Repúbli-

\footnotetext{
94 D'FILIPPO, Mario Alario. Conceptualización de la Función Social de la Propiedad en el Derecho Español y Colombiano. Jurídica, Cartagena (Colombia), v. 8, n. 16, p. 176-191, 2016.

95 PASQUALE, María Florencia. La función social de la propiedad en la obra de león duguit: una re-lectura desde la perspectiva historiográfica. Red de Revistas Cientificas de América Latina, el Caribe, España y Portugal Sistema de Información Cientifica, Historia Constitucional, n. 15, p. 93-111, ene./dec. 2014.

96 COLOMBIA. Corte Constitucional. Sentencia C-595/99.
} 
ca, Ricardo Lagos Escobar ${ }^{97}$. En efecto, introduciéndose una serie de modificaciones al Decreto Ley 211, de $1973,{ }^{98}$ dictado por el General Pinochet en diciembre, con una norma encaminada a fijar normas para la defensa de la libre competencia, propias de un sistema de libre mercado. No obstante, como se indicaba, no es hasta el 2003 que se crea un Tribunal como órgano jurisdiccional especial e independiente, sujeto a la superintendencia directiva, correccional y económica de la Excelentísima Corte Suprema, cuya función será prevenir, corregir y sancionar los atentados a la libre competencia, según nos recuerda el artículo 7, aunque hoy, por las diversas modificaciones a su texto original ${ }^{99}$, es el artículo 5. La misma norma reformada, también consagra que lo que está en contraposición de la libre competencia ${ }^{100}$, todo lo que

97 CHILE. Ley 19911, “CREA EL TRIBUNAL DE LA LIBRE COMPETENCIA". Ministerio de Economía, Fomento y Reconstrucción, publicada el 14 de noviembre de 2003. Disponible en: https://www.leychile.cl/Navegar?idNorma=217122. Acceso en: 22 jul. 2019.

98 CHILE. Decreto Ley 211, "FIJA NORMAS PARA LA DEFENSA DE LA LIBRE COMPETENCIA". Ministerio de Economía, Fomento y Reconstrucción, publicado el 17 de diciembre de 1973, última modificación de la Ley 20088, de 5 de enero de 2006. Disponible en: https://www.leychile.cl/Navegar?idNorma=5872 Acceso en: 22 jul. 2019.

99 CHILE. Fiscalía Nacional Económica. "Decreto Ley 211 que fja normas para la defensa de la libre competencia. Versión refundida”, publicada en el sitio electrónico de la institución en 2016. Disponible en: https://www.fne.gob.cl/wp-content/uploads/2010/12/DL_211_ refundido_2016.pdf. Acceso en: 22 de julio de 2019.

100 De acuerdo con el artículo 3, inciso segundo, se consagra al respecto que: Se considerarán, entre otros, como hechos, actos o convenciones que impiden, restringen o entorpecen la libre competencia o que tienden a producir dichos efectos, los siguientes:

Los acuerdos o prácticas concertadas que involucren a competidores entre sí, y que consistan en fijar precios de venta o de compra, limitar la producción, asignarse zonas o cuotas de mercado o afectar el resultado de procesos de licitación, así como los acuerdos o prácticas concertadas que, confiriéndoles poder de mercado a los competidores, consistan en determinar condiciones de comercialización o excluir a actuales o potenciales competidores.

La explotación abusiva por parte de un agente económico, o un conjunto de ellos, de una posición dominante en el mercado, fijando precios de compra o de venta, imponiendo a una venta la de otro producto, asignando zonas o cuotas de mercado o imponiendo a otros abusos semejantes.

Las prácticas predatorias, o de competencia desleal, realizadas con el objeto de alcanzar, mantener o incrementar una posición dominante. La participación simultánea de una persona en cargos ejecutivos relevantes o de director en dos o más empresas competidoras entre sí, siempre que el grupo empresarial al que pertenezca cada una de las referidas empresas tenga ingresos anuales por ventas, servicios y otras actividades del giro que excedan las cien mil unidades de fomento en el último año calendario. Con todo, sólo se materializará esta infracción si transcurridos noventa días corridos, contados desde el término del año calendario en que fue superado el referido será en beneficio de los consumidores.

Además, hay que tener presente la ley 20.169, que regula la competencia desleal, de $2007^{101}$. Esta ley es fundamental en el ejercicio jurisdiccional de los particulares, pues de acuerdo con ella, cualquier competidor, consumidor y en general cualquier persona afectada en sus intereses legítimos por un acto de competencia desleal ${ }^{102}$ puede presentar acciones legales. Así, se estatuye

umbral, se mantuviere la participación simultánea en tales cargos.

La norma citada está contenida en: CHILE. Fiscalía Nacional Económica. "Decreto Ley 211 que fija normas para la defensa de la libre competencia. Versión refundida”, publicada en el sitio electrónico de la institución en 2016. Disponible en: https://www.fne.gob.cl/wpcontent/uploads/2010/12/DL_211_refundido_2016.pdf. Acceso en: 22 de julio de 2019.

101 CHILE. Ley 20169 "REGULA LA COMPETENCLA DESLEAL”. Ministerio de Economía, Fomento y Reconstrucción, publicado el 16 de febrero de 2007, última versión de 4 de julio de 2019, por modificación de la Ley 21166, de 4 de julio de 2019. Disponible en: https://www.leychile.cl/Navegar?idNorma=258377. Acceso en: 22 jul. 2019.

102 En virtud del artículo 4 de la Ley 20.169, Regula la competencia desleal, y sin que la enumeración sea taxativa, se considerarán actos de competencia desleal los siguientes:

Toda conducta que aproveche indebidamente la reputación ajena, induciendo a confundir los propios bienes, servicios, actividades, signos distintivos o establecimientos con los de un tercero.

El uso de signos o la difusión de hechos o aseveraciones, incorrectos o falsos, que induzcan a error sobre la naturaleza, proveniencia, componentes, características, precio, modo de producción, marca, idoneidad para los fines que pretende satisfacer, calidad o cantidad $y$, en general, sobre las ventajas realmente proporcionadas por los bienes o servicios ofrecidos, propios o ajenos.

Todas las informaciones o aseveraciones incorrectas o falsas sobre los bienes, servicios, actividades, signos distintivos, establecimientos o relaciones comerciales de un tercero, que sean susceptibles de menoscabar su reputación en el mercado. Son también ilícitas las expresiones dirigidas a desacreditarlos o ridiculizarlos sin referencia objetiva.

d) Las manifestaciones agraviantes que versen sobre la nacionalidad, las creencias, ideologías, vida privada o cualquier otra circunstancia personal del tercero afectado y que no tenga relación directa con la calidad del bien o servicio prestado.

Toda comparación de los bienes, servicios, actividades o establecimientos propios o ajenos con los de un tercero, cuando se funde en algún antecedente que no sea veraz y demostrable, o, cuando de cualquiera otra forma infrinja las normas de esta ley.

Toda conducta que persiga inducir a proveedores, clientes u otros contratantes a infringir los deberes contractuales contraídos con un competidor.

El ejercicio manifiestamente abusivo de acciones judiciales con la finalidad de entorpecer la operación de un agente del mercado.

La imposición por parte de una empresa a un proveedor, de condiciones de contratación para sí, basadas en aquellas ofrecidas por ese mismo proveedor a empresas competidoras de la primera, para efectos de obtener mejores condiciones que éstas; o, la imposición a un proveedor de condiciones de contratación con empresas competidoras de la empresa en cuestión, basadas en aquellas ofrecidas a ésta. A modo de ejemplo, se incluirá bajo esta figura la presión 
que contra actos de competencia desleal se pueden ejercer una, conjunta o separadamente las siguientes acciones:

a) La Acción de cesación del acto o de prohibición del mismo si aún no se ha puesto en práctica.

b) La Acción declarativa de acto de competencia desleal, si la perturbación creada por el mismo subsiste.

c) La Acción de remoción de los efectos producidos por el acto, mediante la publicación de la sentencia condenatoria o de una rectificación a costa del autor del ilícito u otro medio idóneo.

d) La Acción de indemnización de los prejuicios ocasionados por el acto, sujeta a las disposiciones del Título XXXV del Libro IV del Código Civil.

En doctrina, se han analizado estas acciones, analizando si son un régimen acumulativo o alternativo de acciones. En efecto, Fernández Ortega, alude a que este régimen o forma de interposición es parcial, pues en algunos casos, es necesaria una resolución declarativa, especialmente cuando se trata de indemnizaciones. No obstante, a ello, se otorga las herramientas jurídicas adecuadas para la protección de la competencia leal entre los diversos agentes del mercado ${ }^{103}$. Consecuencia de ello, es que el emprendimiento, ya sea ejercido por

verbal o escrita, que ejerza una empresa a un proveedor de menor tamaño cuyos ingresos dependen significativamente de las compras de aquélla, para obtener un descuento calculado a partir del precio pactado por ese mismo proveedor con algún competidor de la primera empresa.

El establecimiento o aplicación de cláusulas contractuales o conductas abusivas en desmedro de los proveedores, el incumplimiento sistemático de deberes contractuales contraídos con ellos o de los plazos dispuestos en la ley $\mathrm{N}^{\circ} 19.983$ para el cumplimiento de la obligación de pago del saldo insoluto contenido en la factura.

Sin perjuicio de lo anterior, y cualquiera sea la naturaleza jurídica del deudor, la empresa de menor tamaño afectada podrá demandar el monto de los perjuicios que deriven del incumplimiento, de acuerdo a las normas generales. La acción podrá ser ejercida por el afectado, por sí, en demanda colectiva o representado por la entidad gremial que les agrupe, todo ello de acuerdo a lo dispuesto en el artículo noveno números dos al cinco de la ley que fija normas especiales para empresas de menor tamaño.

La norma citada está contenida en: CHILE. Ley 20169 "REGULA LA COMPETENCLA DESLEAL". Ministerio de Economía, Fomento y Reconstrucción, publicado el 16 de febrero de 2007, última versión de 4 de julio de 2019, por modificación de la Ley 21166, de 4 de julio de 2019. Disponible en: https://www.leychile.cl/ Navegar?idNorma=258377. Acceso en: 22 jul. 2019.

103 FERNÁNDEZ ORTEGA, Felipe. Una mirada al régimen alternativo y acumulativo del sistema de acciones de la Ley de Competencia Desleal en la judicatura nacional. Revista Justicia y Derecho, Chile, v. 1, n. 1, p. 89-99, 2018. una persona natural o jurídica, tiene a su haber acciones especiales de protección para actuar en condiciones de igualdad en el mercado, o, al menos aquellas que no generen una desigualdad ocasionada de malas prácticas.

En cuanto al procedimiento, en general se hace un envío a las reglas generales según la Ley 20.169, que regula la competencia desleal ${ }^{104}$. El tribunal competente para conocer de las causas de competencia desleal, lo será el juzgado de letras en lo civil del domicilio del demandado o del actor, a elección de este último, según dispone el artículo 8. El procedimiento será sumario, de acuerdo con las normas del Código de Procedimiento Civil, artículos 680 y siguientes ${ }^{105}$, siendo breve en comparación a los juicios de lato conocimiento, siendo esencialmente escrito y con un término probatorio de 8 días hábiles. Se admiten todos los recursos procesales que franquea la legislación, según dispone el artículo 9.

Pero, además, el procedimiento sigue si existe sentencia firme donde se haya establecido que ha existió uno o más actos de competencia desleal. En efecto, según dispone el artículo 10 de la Ley 20.169, que regula la competencia desleal ${ }^{106}$, el tribunal que dictó la resolución deberá remitir todos los antecedentes del juicio al Fiscal Nacional Económico, quien tendrá la facultad de requerir al Tribunal de Defensa de la Libre Competencia, atendidas la gravedad de la infracción o la extensión del perjuicio provocado, la aplicación de una multa, de entre 2 y 1.000 unidades tributarias mensuales, y se aplicará a beneficio fiscal.

104 CHILE. Ley 20169 "REGULA LA COMPETENCIA DESLEAL”. Ministerio de Economía, Fomento y Reconstrucción, publicado el 16 de febrero de 2007, última versión de 4 de julio de 2019, por modificación de la Ley 21166, de 4 de julio de 2019. Disponible en: https:/ / www.leychile.cl/Navegar?idNorma=258377. Acceso en: 22 jul. 2019.

105 CHILE. Ley 1552, “CÓDIGO DE PROCEDIMIENTO CIVIL”. Ministerio de Justicia, publicado el 30 de agosto de 1902, última versión de 14 de mayo de 2019, por modificación de la Ley 21159, de 14 de mayo de 2019. Disponible en: https:/ / www.leychile.cl/Navega r?idNorma $=1131420 \&$ \&idParte $=10022142 \&$ idVersion $=2019-05-14$. Acceso en: 22 jul. 2019.

106 CHILE. Ley 20169 "REGULA LA COMPETENCIA DESLEAL”. Ministerio de Economía, Fomento y Reconstrucción, publicado el 16 de febrero de 2007, última versión de 4 de julio de 2019 , por modificación de la Ley 21166, de 4 de julio de 2019. Disponible en: https://www.leychile.cl/Navegar?idNorma $=258377$. Acceso en: 22 jul. 2019. 


\section{Conclusiones y perspectivas de futuro. De libertad de emprender a un derecho justiciable, pero siempre en armonía con otros.}

Con el estudio realizado es posible afirmar que, tanto en un Estado neoliberal (Chile) como en un Estado social (Colombia), en la actualidad se convive con el libre mercado. No obstante, vale que añadir que la inserción del estado social de derecho en Colombia tiene mucho de estrategia retórica, al punto que en la práctica la Constitución de 1991 realmente consagró un estado social de derecho neoliberal, es decir una especie de contradictio in adiecto u oximoron. Ello ha generado que, al emprendimiento, sea realizado por personas naturales y jurídicas, se les reconozca una serie de derechos y libertades fundamentales.

Cuando se trata de emprendimiento la propia esencia del concepto, implica de modo natural que un agente económico acomete ex nibilo una actividad económica que tienen como objetivo general la creación de riqueza, esta es una verdad irrecusable. Desde Adam Smith, pasando por Hayeck y Von Mises hasta Ronal Coase, el lema fundamental es que la codicia individual de los agentes se convierte en una virtud pública o colectiva, pues la generación de riqueza desata productos marginales que van más allá del lucro o la ganancia. Admitido entonces que el lucro aspira a impulsar las acciones de las personas, como lo tiene analizado la praxeología, la perspectiva o arista social del emprendimiento lleva a indagar cuál es el destino final del lucro. Las utilidades o ganancias de una empresa tienen como destino fatal e inexorable los impuestos. El EBITDA en el lenguaje económico, uno de los índices financieros más conocidos, que no se puede descartar como herramienta del análisis de cualquier empresa, es la síntesis de las expresiones nominadas en idioma inglés como Earnings Before Interest, Taxes, Depreciation, and Amortization, que significan ganancias antes de intereses, impuestos, depreciación y amortización.

Lo que queremos decir con esto es que los impuestos, por sólo tomar una de las variables de la sigla EBITDA, son la socialización de las ganancias resultante del esfuerzo individual en una economía de mercado. No obstante, los impuestos son anteriores al Estado mismo, las ofrendas de sacrificios a los dioses para que estos protegieron a toda la comunidad eran una forma de compartir solidariamente el resultado de la actividad económica. Las barreras artificiales a la entrada de un mercado son constitutivas de conductas atentatorias de la libre competencia. Un emprendedor puede verse enfrentado a barreras artificiales, pero partiendo de que ellas no existan, o que sean controladas por la autoridad de competencia, hay barreras naturales como la falta de experiencia, escasa capacidad técnica o necesidades de ingentes cantidades de dinero para iniciar, lo que puede inhibir el emprendimiento.

Ante este panorama, surge la duda, tanto en Chile como en Colombia, qué pasaría si el gobierno establece exenciones tributarias, créditos subsidiados, amnistías o beneficios para emprendedores. A primera vista, una política de esa naturaleza violaría el principio de igualdad formal, pues discriminaría de los beneficios a los empresarios ya establecidos. No obstante, el entendimiento de que el derecho de igualdad no es una regla puramente formal, sino que apareja tratar de modo igual a los iguales y diferente a los diferentes, justificaría constitucionalmente una ley que establecerá privilegios para los emprendedores. Obsérvese que los empresarios ya establecidos podrían poner barreras a la entrada, reclamando al juez constitucional te expulse del ordenamiento jurídico, esto es, que declare contraria a la Constitución una ley que establezca una exención de impuestos o intereses subsidiados. Al así proceder estaría creando una barrera a la entrada y garantizar el segundo monopolio o un oligopolio con la ayuda del juez constitucional.

Tan solo este año el decreto 286 dispuso un incentivo tributario para empresas que se ajustan a la visión de emprendimiento que el presidente Iván Duque ha decidido llamar de economía naranja. Según este "Las rentas provenientes del desarrollo de industrias de valor agregado tecnológico y actividades creativas, por un término de siete (7) años ${ }^{\prime 107}$. En un debate de este estilo, el derecho constitucional podría construir razonamientos sobre la defensa de la libre competencia económica. En este caso la libre competencia económica estaría definitivamente

107 COLOMBIA. DECRETO 286 DE 2020, "POR EL CUAL SE REGLAMENTA EL NUMERAL 1 DEL ARTÍCULO 235-2 DEL ESTATUTO TRIBUTARIO Y SE SUSTITUYEN UNOS ARTÍCULOS DEL CAPÍTULO 22 DEL TÍTULO 1 DE LA PARTE 2 DEL LIBRO 1 DEL DECRETO 1625 DE 2016 ÚNICO REGLAMENTARIO EN MATERIA TRIBUTARIA", Congreso de la Republica, Publicado en mayo, 2019. Disponible en: http://www. suin-juriscol.gov.co/viewDocument.asp?ruta=Leyes $/ 30030647$. Acceso en: Febrero 2020. 
protegida garantizando el ingreso de nuevos agentes al mercado pues la competencia entre todos ellos, en el mayor número posible, reduciría los precios en beneficio del grupo de consumidores. Un adecuado ejercicio de hermenéutica jurídica podría tener enormes efectos para proteger simultáneamente el emprendimiento y la libre competencia económica.

Nos sobra añadir que en Colombia están consagradas en la Carta Política otras acciones muy importantes como la acción popular prevista en el artículo 88 de la Constitución. Según esta norma se defiere a la ley la creación de acciones populares para la defensa de la libre competencia económica. De esta manera, el grupo de consumidores podría proponer acciones constitucionales privilegiadas, para atacar los actos atentatorios de la libre competencia y exigir la indemnización a que tendrían derecho dichos consumidores afectados con la conducta anticompetitiva.

De nuevo emerge la consideración acerca de subjetividades distintas, pues, aunque las acciones populares y del grupo, así como los derechos difusos, ya tienen mucha tradición. Es por ello por lo que la circunstancia de que en Colombia haya sido consagrada una acción constitucional para la protección de la libre competencia tiene un influjo importantísimo en materia de emprendimiento. Se ha tomado el camino de proteger a los consumidores sancionando los actos de competencia desleal no sólo en sede administrativa si no con esencia reparatoria para las víctimas colectivas.

De otro lado, se evidencia del estudio que, en ambos sistemas jurídicos, el chileno y el colombiano, hoy en día se es sujeto activo legitimado de una serie de acciones o recursos. Y, no sólo se queda en sede judicial ordinaria, sino que también, puede accederse a sede constitucional, a través del recurso de amparo constitucional (recurso de protección y recurso de amparo en Chile, y, en Colombia, con la acción de tutela).

No obstante, a lo anterior, cuando se trate de derechos fundamentales, los tribunales, tanto en aspectos de competencia, como cuando se generan conflictos de derechos, deben ponderar en favor de aquellos derechos y libertades intrínsecas con la persona humana. Así, por ejemplo, si se persigue una indemnización por una empresa, tendrá que acudir a justicia ordinaria y no a procedimientos constitucionales, que son en general, más breves, rápidos y con preferencia de vista en la Cortes. En tal sentido, juega un rol relevante, y, por ello, de es- pecial protección la libre competencia. Así, Colombia lo ha elevado a nivel constitucional, mientras que en Chile queda regulado solo a nivel legal, sin perjuicio que también podría intentarse acciones constitucionales como el recurso de protección, pero deja en la posibilidad de ponderar al caso concreto a la Corte, es decir, si es la vía más idónea o bien, dejarlo solo para jurisdicción especial.

Y, sumado a lo previamente dicho, la actividad económica debe convivir con los derechos de las personas, es decir, que puedan realizar emprendimiento, pero sin vulnerar, o al menos sin superar los límites impuestos por la Constitución y/o las leyes. Ello, tal como lo han expuesto en detalle otros colegas, en relación con las repercusiones que puede tener la actividad empresarial cuando es desmedida y afecta, no solo a las personas y sus derechos intrínsecos, sino que también, al medio ambiente.

Por todo lo anterior es que hablamos de una moneda de dos caras, en que además se debe considerar el contexto en que se encuentra, es decir, en Latinoamérica donde el emprendimiento en ocasiones no es una opción sino una vía de subsistencia. Así, una cara, es la libertad de emprender, pero al mismo tiempo, se genera la necesidad de elevarlo a un derecho, que debe ser resguardado especialmente en los pequeños y microempresarios, con énfasis a quienes lo ejercen como una actividad de subsistencia. Sin embargo, la otra cara de la moneda son los derechos y libertades que pueden verse afectados de otras personas individualmente consideradas, de la comunidad en su conjunto y del medio ambiente. El justo equilibro entre estas dos caras, es una necesidad que debe replicarse a nivel principios, idealmente consagrándose en cuerpos normativos relevantes como Tratados Internacionales sobre derechos humanos, la Constitución de cada país, y, otorgándoles las acciones, recursos e institucionalidad adecuada para hacerlos efectivos.

\section{Referências}

ALVEAR TÉLLEZ, Julio. La jurisprudencia del amparo económico los tres grandes déficits de la última década. Estudios Constitucionales, Chile, v. 11, n. 1, p. 167-220, 2013.

ARAYA ROSALES, Andrés; GALLARDO ALTAMI- 
RANO, Mauricio. El Modelo Chileno desde una ética de justicia y de igualdad de las oportunidades humanas. Polis, Chile, v. 14, n. 40, p. 265-287, 2015.

ATIENZA, Miguel; LUFÍN, Marcelo; ROMANÍ, Gianni. Un Análisis espacial del emprendimiento en Chile. Más no siempre es mejor. Eure, Chile, v. 42, n. 127, pp. 111-135, 2016.

AUZ VACA, Juan Gabriel. The environmental law dimensions of an international binding treaty on business and human rights. Brazilian Journal of International Law, Brasilia, v. 15, n. 2, p. 152-187, 2018.

BORDALÍ SALAMANCA, Andrés. El recurso de protección entre exigencias de urgencia y seguridad jurídica. Revista de Derecho (Valdivia), Chile, v. 19, n. 2, p. 205228, 2006.

BULLARD, Alfredo. La prohibición imposible. ¿Cómo tratar a los monopolios en la Constitución? Revista de la Facultad de Derecho (PUCP), Perú, n. 56, pp, 759-793, 2003.

CAPUCIO, Camilla. National judges and courts as institutions for global economic governance. Brazilian Journal of International Law, Brasilia, v. 12, n. 2, p. 255369, 2015.

CARRERA SILVA, Liliana. La acción de tutela en Colombia. Revista Ius, Puebla, v. 5, n. 27, p. 72-94, 2011.

CASTRO, José Miguel Camacho. El papel de las instituciones de control financiero sobre los derechos humanos en el contexto latinoamericano. Brazilian Journal of International Law, Brasilia, v. 13, n. 1, p. 156-168, 2016.

CHILE. Constitución Política de la República de Cbile. 16 jun. 2018. Disponible em: https://www.leychile.cl/ Navegar?idNorma=242302. Acceso en: 22 jul. 2019.

CHILE. Constitución Politica del Estado de Chile, de 30 de octubre de 1822. Disponible em: https:/ / www.leychile.cl/ Navegar?idNorma=1005168. Acceso en: 22 jul. 2019.

CHILE. Decreto Ley 1350, "CREA LA CORPORACIÓN NACIONAL DEL COBRE DE CHILE”. Ministerio de Minería, publicado el 28 de febrero de 1976, 9 ene. 2014, por modificación de la Ley 20720. Disponible en: https://www.leychile.cl/ Navegar?idNorma=6578\&idParte. Acceso en: 22 jul. 2019.

CHILE. Decreto Ley 1552, "ACTA COSTITUCIO$N A L N^{\circ}$ 3. De los derechos y deberes constitucionales". Mi- nisterio de Justicia, publicado el 13 de septiembre de 1976. Disponible en: https://www.leychile.cl/ Navegar?idNorma=6656 Acceso en: 22 jul. 2019.

CHILE. Decreto Ley 211, "FIJA NORMAS PARA LA DEFENSA DE LA LIBRE COMPETENCIA”. Ministerio de Economía, Fomento y Reconstrucción, publicado el 17 de diciembre de 1973, última modificación de la Ley 20088, de 5 de enero de 2006. Disponible en: https://www.leychile.cl/Navegar?idNorma $=5872$ Acceso en: 22 jul. 2019.

CHILE. Excelentísima Corte Suprema. Auto Acordado 94-2015. "TEXTO REFUNDIDO DEL AUTO ACORDADO SOBRE TRAMITACIÓN Y FALLO DEL RECURSO DE PROTECCIÓN DE LAS GARANTÍAS CONSTITUCIONALES", publicado el 28 de agosto de 2015, última versión de 5 de octubre de 2018, por modificación del Auto Acordado 173 de 5 de octubre de 2018. Disponible en: https://www.leychile. cl/Navegar?idNorma=1080916 Acceso en: 22 jul. 2019.

CHILE. Excelentísima Corte Suprema. Rol No 11.9572018. Sentencia de 05 de mayo de 2018.

CHILE. Excelentísima Corte Suprema. Rol No 4.2442019. Sentencia de 28 de febrero de 2019.

CHILE. Fiscalía Nacional Económica. "Decreto Ley 211 que fija normas para la defensa de la libre competencia. Versión refundida”, publicada en el sitio electrónico de la institución en 2016. Disponible en: https://www.fne. gob.cl/wp-content/uploads/2010/12/DL_211_refundido_2016.pdf. Acceso en: 22 de julio de 2019.

CHILE. Ilustrísima Corte de Apelaciones de Concepción. Rol $N^{\circ}$ 7.178-2017. Sentencia de 11 de mayo de 2018.

CHILE. Ley 1552, "CÓDIGO DE PROCEDIMIENTO CIVIL”. Ministerio de Justicia, publicado el 30 de agosto de 1902, última versión de 14 de mayo de 2019, por modificación de la Ley 21159, de 14 de mayo de 2019. Disponible en: https://www.leychile.cl/Naveg ar?idNorma $=1131420 \& i d P a r t e=10022142 \& i d V e r s i$ on=2019-05-14. Acceso en: 22 jul. 2019.

CHILE. Ley 18971, "ESTABLECE RECURSO ESPECLAL QUE INDICA”. Ministerio de Economía, Fomento y Reconstrucción, publicada el 10 de marzo de 1990. Disponible en: https://www.leychile.cl/ Navegar?idNorma=30339. Acceso en: 22 jul. 2019.

CHILE. Ley 19911, “CREA EL TRIBUNAL DE LA 
LIBRE COMPETENCIA”. Ministerio de Economía, Fomento y Reconstrucción, publicada el 14 de noviembre de 2003. Disponible en: https://www.leychile.cl/ Navegar?idNorma=217122. Acceso en: 22 jul. 2019.

CHILE. Ley 20169 "REGULA LA COMPETENCLA DESLE AL”. Ministerio de Economía, Fomento y Reconstrucción, publicado el 16 de febrero de 2007, última versión de 4 de julio de 2019, por modificación de la Ley 21166, de 4 de julio de 2019. Disponible en: https://www.leychile.cl/Navegar?idNorma=258377. Acceso en: 22 jul. 2019.

CHILE. Ley 20169 "REGULA LA COMPETENCIA DESLEAL”. Ministerio de Economía, Fomento y Reconstrucción, publicado el 16 de febrero de 2007, última versión de 4 de julio de 2019, por modificación de la Ley 21166, de 4 de julio de 2019. Disponible en: https:/ / www.leychile.cl/Navegar?idNorma=258377. Acceso en: 22 jul. 2019.

CHILE. Ley 20169 "REGULA LA COMPETENCIA DESLEAL”. Ministerio de Economía, Fomento y Reconstrucción, publicado el 16 de febrero de 2007, última versión de 4 de julio de 2019, por modificación de la Ley 21166, de 4 de julio de 2019. Disponible en: https:/ /www.leychile.cl/Navegar?idNorma=258377. Acceso en: 22 jul. 2019.

CHILE. Ministerio de Economía, Fomento y Turismo. Informe de resultados: Empresas en Chile. Cuarta Encuesta Longitudinal de Empresas. Agosto 2017. Disponible en: https://www.economia.gob.cl/wp-content/uploads $/ 2017 / 03 /$ Bolet $\%$ C3\%ADn-empresas-en-ChileELE4.pdf. Acceso en: 28 jul. 2019.

CHONCHOL, Jacques. Impacto de la globalización en las sociedades latino-americanas: ¿qué hacer frente a ello?. Estudos Avançados, Brasil, v. 12, n. 34, p. 163-186, 1998.

COBO, Nicolás. Ley de rotulación de alimentos de Chile: ¿Traba comercial o protección de la salud?. Brazilian Journal of International Law, Brasilia, v. 14, n. 3, p. 260275, 2017.

COLOMBIA. Comisión de Regulación de Comunicaciones. Caso Tigoune del 05 de octubre De 2016. Disponible en: https://www.crcom.gov.co/recursos_user/2016/Actividades_regulatorias/merc_moviles/coment2/2016LA_PROTECCION_CONSTITUCIONAL_DE_ LA_LIBRE_COMPETENCIA.pdf. Acceso en: 01 ago. 2019.
COLOMBIA. Corte Constitucional. C-263 2011. M.P Jorge Ignacio Pretelt Chaljub.

COLOMBIA. Corte Constitucional. C-537 2010. M.P Juan Carlos Henao Pérez.

COLOMBIA. Corte Constitucional. C-836 de 2001. M.P. Rodrigo Escobar Gil.

COLOMBIA. Corte Constitucional. Sentencia C-228 de 24 de marzo 2010. M.P. Luis Ernesto Vargas Silva.

COLOMBIA. Corte Constitucional. Sentencia C-263/11. M.P. Jorge Ignacio Pretelt Chaljub.

COLOMBIA. Corte Constitucional. Sentencia C-535 del 97. M.P. Eduardo Cifuentes Muñoz.

COLOMBIA. Corte Constitucional. Sentencia C-595/99.

COLOMBIA. Corte Constitucional. Sentencia SU448/2011. M.P. Mauricio Gonzales Cuervo.

COLOMBIA. Corte Constitucional. Sentencia T 1145 de 2005. M.P. Rodrigo Escobar Gil.

COLOMBIA. Corte Constitucional. Sentencia T 378 de 2006. M.P. Clara Inés Vargas Hernández.

COLOMBIA, Corte Constitucional. Sentencia T 472 de 1996. M.P. Eduardo Cifuentes Muñoz.

COLOMBIA. Corte Constitucional. Sentencia T-378/2006. M.P. Clara Inés Vargas Hernández.

COLOMBIA. Corte Constitucional. Sentencia T-396/93. M.P. Vladimiro Naranjo Mesa.

COLOMBIA. Corte Constitucional. Sentencia T-830/10. M.P. Luis Ernesto Vargas Silva.

COLOMBIA. DECRETO 286 DE 2020, "POR EL CUAL SE REGLAMENTA EL NUMERAL 1 DEL ARTÍCULO 235-2 DEL ESTATUTO TRIBUTARIO Y SE SUSTITUYEN UNOS ARTÍCULOS DEL CAPÍTULO 22 DEL TÍTULO 1 DE LA PARTE 2 DEL LIBRO 1 DEL DECRETO 1625 DE 2016 ÚNICO REGLAMENTARIO EN MATERIA TRIBUTARIA", Congreso de la Republica, Publicado en mayo, 2019. Disponible en: http://www.suin-juriscol.gov.co/ viewDocument.asp?ruta $=$ Leyes $/ 30030647$. Acceso en: Febrero 2020.

COLOMBIA. Ley 1834 DE 2019. "POR MEDIO DE LA CUAL SE FOMENTA LA ECONOMÍA CREATIVA LEY NARANJA EL CONGRESO DE COLOMBIA", Congreso de la Republica, Publicado en mayo, 2019. Disponible en: http://www.suin-juriscol. 
gov.co/viewDocument.asp?ruta=Leyes $/ 30030647$. Acceso en: 10 abril 2019.

COLOMBIA. Ley 590 DE 2000. "Por la cual se dictan disposiciones para promover el desarrollo de las micro, pequeñas y medianas empresa" Congreso de la Republica, Publicado en junio, 2000. Disponible en: http://www.suin-juriscol.gov.co/viewDocument. asp?ruta=Leyes/30030647 Acceso en: 10 abril 2019.

COLOMBIA. Constitución Politica de 1991. Disponible en: http://www.suin-juriscol.gov.co/viewDocument. asp?ruta $=$ Constitucion $/ 1687988$. Acceso en: 25 mayo 2019.

CONFECÁMARAS. Dinámica de creación de empresas en Colombia. Enero-diciembre de 2019. Disponible en: http://www.confecamaras.org.co/phocadownload/2019/Cuadernos_Analisis_Economicos/ Din $\%$ C3 $\%$ A1mica $\% 20$ de $\% 20$ Creaci $\%$ C3 $\%$ B 3n $\% 20$ de $\% 20$ Empresas $\% 20 \_\% 20$ Ene-Dic $\% 202019 \% 20$ _21012020.pdf Acesso en: 8 abr. 2020.

CORTE INTERAMERICANA DE DERECHOS HUMANOS. Sentencia de 21 de junio de 2002. Caso Hilaire, Constantine y Benjamin y otros contra Trinidad y Tobago de 2002. Disponible en: http://www.corteidh. or.cr/docs/casos/articulos/Seriec_94_esp.pdf. Acceso en: 28 jul. 2019.

D’FILIPPO, Mario Alario. Conceptualización de la Función Social de la Propiedad en el Derecho Español y Colombiano. Jurídica, Cartagena (Colombia), v. 8, n. 16, p. 176-191, 2016.

DÍAZ FUENZALIDA, Juan Pablo. ¿Son parte del bloque de constitucionalidad los principales tratados internacionales de derechos humanos de la ONU en Chile? Del texto positivo a la aplicación en tribunales de justicia. Revista Brasileira de Políticas Públicas, Brasilia, v. 9, n. 1, p. 153-171, 2019.

AMARAL, Junior do; PALACIO REVELLO, Viviana. Human rights and extractive industries in Latin America: what responsibility of corporations and their States of origin for human rights violations in the Inter-American Rights System? Brazilian Journal of International Law, Brasilia, v. 15, n. 2, p. 244-252, 2018.

DUARTE, Tito; RUIZ TIBANA, Myriam. Emprendimiento, una opción para el desarrollo. Scientia Et Technica, Colombia, v. 15, n. 43, p. 326-331, 2009.

FERMANDOIS VÖHRINGER, Arturo. El Orden
Público Económico bajo la Constitución de 1980. Ius Publicum, Chile, n. 4, p. 63-78, 2000.

FERNÁNDEZ ORTEGA, Felipe. Una mirada al régimen alternativo y acumulativo del sistema de acciones de la Ley de Competencia Desleal en la judicatura nacional. Revista Justicia y Derecho, Chile, v. 1, n. 1, p. 89-99, 2018.

FERRANTE, Alfredo. Entre derecho comparado y derecho extranjero. Una aproximación a la comparación jurídica. Revista chilena de derecho, Santiago, v. 43, n. 2, p. 601-618, 2016.

FERRAZ, Daniel Amin. Grupo de sociedades: instrumento jurídico de organização da empresa plurissocietária. Brazilian Journal of International Law, Brasilia, v. 12, n. 2, p. 494-510, 2014.

FERRAZ, Daniel Amin. Horizontal agreements, vertical agreements and European and north American jurisprudence on the matter. Brazilian Journal of International Law, Brasilia, v. 9, n. 2, p. 150-160, 2012.

FERRAZ, Daniel Amin. O grupo de sociedades: mecanismo de inserção da empresa transnacional na nova ordem econômica internacional. Brazilian Journal of International Law, Brasilia, v. 9, n. 1, p. 15-25, 2012.

GINSBURG, Tom; MELTON, James. Innovation in Constitutional Rights. Draft for presentation at NYU Workshop on Law, Economics and Politics, p. 1-29, 2012.

GOMEZ, Eduardo Biacchi; MARINOZZI, Julia Colle. O diálogo entre fontes normativas e o controle de convencionalidade: entre o livre comércio e o desenvolvimento econômico e sustentável. Brazilian Journal of International Law, Brasilia, v. 16, n. 1, p. 186-199, 2019.

HERNÁNDEZ EMPARANZA, Domingo. El recurso de amparo económico: una tendencia jurisprudencial peligrosamente reduccionista. Estudios Constitucionales, Chile, v. 8, n. 1, p. 443-466, 2010.

IORNS, Catherine. "From Rights to Responsibilities using Legal Personhood and Guardianship for Rivers (August 21, 2018). Responsability: Law and Governance for Living Well with the Earth, B Martin, L Te Aho, M Humphries-Kil (eds), Routledge, London \& New York, p. 216-239, 2019.

JOS, Justin. Access to remedies and the emerging ethical dilemmas: changing contours within the businesshuman rights debate. Brazilian Journal of International Law, Brasilia, v. 15, n. 2, p. 117-128, 2018. 
LATORRE VIVAR, Patricio. Las sociedades estatales en el ordenamiento jurídico chileno: Naturaleza, límites y control de sus actividades. Revista de Derecho de la Pontificia Universidad Católica de Valparaíso, Chile, n. 30, p. 223-240, 2008.

LOO GUTIÉRREZ, Martín. La disciplina constitucional del principio de subsidiariedad en Italia y Chile. Revista de Derecho de la Pontificia Universidad Católica de Valparaíso, Chile, n. 33, p. 391-426, 2009.

MANCERA COTA, Adrián. Consideraciones durante el proceso comparativo. Boletín mexicano de derecho comparado, México, v. 41, n. 121, p. 213-243, 2008.

MARÍN CASTILLO, Juan Carlos; TRUJILLO GONZÁLEZ, José Saúl. El Estado Social de Derecho: un paradigma aún por consolidar. Revista Jurídica Derecho, Bolivia, v. 3, n. 4, p. 53-70, 2016.

MATOS, Laura Germano; MATIAS, João Luis Nogueira. Multinacionais fast fashion e direitos humanos: em busca de novos padrões de responsabilização. Brazilian Journal of International Law, Brasilia, v. 15, n. 2, p. $254-$ 268, 2018.

MATOS, Laura Germano; MATIAS, João Luis Nogueira. Zara, M. Officer, Pernambucanas e Serafina/Collins: o padrão condenatório por condições degradantes da mão de obra em redes contratuais do setor de vestuário. Brazilian Journal of International Law, Brasilia, v. 16, n. 3, p. 111-131, 2019.

MENDES Danielle, THAME Denn. Brazilian Journal of International Law, Brasilia, v. 15, n. 2, p. 203-220, 2018.

MÉXICO. "Acta Constitutiva y de Reformas de 1847”. Disponible en: http://museodelasconstituciones.unam. $\mathrm{mx} /$ nuevaweb/wp-content/uploads/2019/02/Actaconstitutiva-y-de-reformas-1847.pdf. Acceso en: 22 jul. 2019.

MÉXICO. Constitución Politica de 1917, última reforma de 29 de enero de 2016. Disponible en: http://www.ordenjuridico.gob.mx/Constitucion/cn16.pdf. Acceso en: 22 jul. 2019.

NACIONES UNIDAS. Pacto Internacional de Derechos Civiles y Politicos, Resolución 2200 A (XXI), de 16 de diciembre de 1966. Disponible em: https://treaties.un.org/ doc/Treaties/1976/03/19760323\%2006-17\%20AM/ Ch_IV_04.pdf. Acceso en: 22 jul. 2019.

NAVARRO BELTRÁN, Enrique. 35 años del recurso de protección notas sobre su alcance y regulación nor- mativa. Estudios Constitucionales, Chile, v. 10, n. 2, p. 617642, 2012.

NOGUEIRA ALCALÁ, Humberto. El Recurso de Protección en el Contexto del Amparo de los Derechos Fundamentales Latinoamericano e Interamericano. Ius et Praxis, Chile, v. 13, n. 1, p. 75-134, 2007.

NOGUEIRA ALCALÁ, Humberto. La acción de constitucionalidad de protección en Chile y la acción de constitucionalidad en México. Ius et Praxis, Chile, v. 16, n. 1, p. 219-286, 2010.

ORGANIZACIÓN DE LOS ESTADOS AMERICANOS. Convención Americana sobre Derechos Humanos, suscrita en la Conferencia especializada interamericana sobre Derechos Humanos (B-32). San José de Costa Rica, del 7 al 22 de noviembre de 1969. Disponible en: https://www.oas. org/dil/esp/tratados_b-32_convencion_americana_ sobre_derechos_humanos.htm. Acceso en: 22 jul. 2019.

OSORIO, Ricardo Serrano; COUTO, Clayton. A defesa comercial e a restrição da liberalização e da integração comercial pelo aumento da alíquota de IPI de veículos importados no Brasil. Brazilian Journal of International Law, Brasilia, v. 10, n. 1, p. 86-95, 2013.

OSSA BOCANEGRA, Camilo Ernesto. Fundamentos de la aplicación pública del derecho de la competencia en Colombia. Revista Facultad de Derecho y Ciencias Politicas, Medellín, v. 44, n. 120, p. 181-219, 2014.

PASQUALE, María Florencia. La función social de la propiedad en la obra de león duguit: una re-lectura desde la perspectiva historiográfica. Red de Revistas Científicas de América Latina, el Caribe, España y Portugal Sistema de Información Científica, Historia Constitucional, n. 15, p. 93-111, ene./dec. 2014.

PEREZ ÁLVAREZ, María del Pilar. La Función Social de la Propiedad Privada. Su protección jurídica. Revista Jurídica de la Universidad Autónoma de Madrid, Madrid, v. 30, n 2., p. 17-47, 2014.

QUINCHE RAMIREZ, M. La acción de tutela elementos dogmáticos y procesales. In: VÍAS de hecho: Acción de tutela contra providencias, 9. ed. Bogotá, D.C.: Editorial Ibañez, 2012. v. 1.

REAL ACADEMIA ESPAÑOLA. Diccionario de la lengua española. Edición del Tricentenario. Actualización 2018, “emprendimiento". Disponible en: https://dle. rae.es/?id=Esj9hsT Acceso en: 28 jul. 2019.

REAL ACADEMIA ESPAÑOLA. Diccionario de la len- 
gua española. Edición del Tricentenario. Actualización 2018, “emprender". Disponible en: https://dle.rae. es/?id=Esip2Nv Acceso en: 28 jul. 2019.

RODRÍGUEZ RAMÍREZ, Alfonso. Nuevas perspectivas para entender el emprendimiento empresarial. Pensam. gest., Colombia, n. 26, p. 94-119, 2009.

RUY CARDIA, Ana Claúdia. Reparation of victims in light of a treaty on business and human rights. Brazilian Journal of International Law, Brasilia, v. 15, n. 2, p. 3-11, 2018.

SANTARELLI, Nicolás Carrillo. Declaraciones empresariales "voluntarias" sobre derechos humanos, y la necesidad de una regulación institucional (internacional e interna) externa. Brazilian Journal of International Law, Brasilia, v. 16, n. 3, p. 21-49, 2019.

SPARANO RADA, Humberto. Emprendimiento en América Latina y su impacto en la gestión de proyectos. Revista Dimensión Empresarial, Colombia, v. 12, n. 2, p. 95-106, 2014.

TRIBUNAL Europeo de Derechos Humanos. Sentencia de 22 de abril de 2012, caso A.C. y otros contra España. Disponible en: http://www.usc.es/export9/ sites/webinstitucional/gl/institutos/ceso/descargas/ STEDH_AC-AND-OTHERS-v-SPAIN_es.pdf Acceso en: 28 de jul. 2019.

VARELA, Marcelo D. A necessidade de repensar os mecanismos de responsabilidade ambiental em caso de riscos de vazamento de petróleo na Zona Econômica Exclusiva do Brasil. Brazilian Journal of International Law, Brasilia, v. 12, n. 1, p. 240-249, 2015.

VATICANO. PÍO XI. Carta Encíclica Quadragesimo anno. "SOBRE LA RESTAURACIÓN DEL ORDEN SOCIAL EN PERFECTA CONFORMIDAD CON LA LEY EVANGÉLICA AL CELEBRARSE EL 40 ANIVERSARIO DE LA ENCÍCLICA "RERUM NOVARUM” DE LEÓN XIII”, dada en Roma, a 15 de mayo de 1931. Disponible en: http://w2.vatican. $\mathrm{va} /$ content/pius-xi/es/encyclicals/documents/hf_pxi_enc_19310515_quadragesimo-anno.html Acceso en: 22 jul. 2019.

VILMONDES TURKE, Mariana Aparecida. Business and human rights in Brazil: exploring human rights due diligence and operational-level grievance mechanisms in the case of Kinross Paracatu gold mine. Brazilian Journal of International Law, Brasilia, v. 15, n. 2, p. 223-241, 2019.
WOODS, Cindy S. Engaging the U.N. Guiding Principles on Business and Human Rights: the Inter-American commission on human rights \& extractive sector. Brazilian Journal of International Law, Brasilia, v. 12, n. 2, p. 572-588, 2015. 
Para publicar na Revista de Direito Internacional, acesse o endereço eletrônico www.rdi.uniceub.br ou www.brazilianjournal.org.

Observe as normas de publicação, para facilitar e agilizar o trabalho de edição. 